\title{
Leadership Survival, Regime Type, Policy Uncertainty and PTA Accession*
}

\author{
James R. Hollyer \\ Yale University \\ B. Peter Rosendorff \\ New York University
}

May 24, 2011

Preferential trade agreements (PTAs) limit member-states' trade policy discretion; consequently policy uncertainty is mitigated. Reductions in policy uncertainty stemming from accession to a PTA improve the resource allocation decisions of the voters and reduce deadweight losses from the need to self-insure against policy uncertainty. The resultant increase in efficiency improves an incumbent government's - particularly a democratic government's - chance of surviving in office. We test this prediction using survival analysis, adjusting for potential selection biases using propensity score matching. We find robust support for the proposition that governments that sign PTAs survive longer in office than observationally similar governments that do not sign. And we find that this effect is stronger in democracies than in autocracies.

${ }^{*}$ We would like to thank participants in the 2010 APSA panel on Trade and Politics and in the 2011 PEIO conference for their comments and suggestions. All remaining errors are our own. 
Preferential trade agreements (PTAs) have become ubiquitous in the international arena. Almost all countries of the world have joined at least one PTA, and more than 185 agreements are listed by the World Trade Organization (WTO) as currently in force. These agreements vary in scope, depth and membership. They all however, codify and clarify the permitted policy choices by member states. As such, they reduce the volatility of trade policy and limit the trade-policy uncertainty experienced by domestic actors.

The effect of international trading arrangements on policy uncertainty helps to shape a government's decision of whether or not to sign a PTA. Signing a PTA serves to commit a government to adopting a known set of policies and establishes transparent mechanisms for changing trade policy within the limits of the trade agreement. While committing to binding tariff levels may have important income distributional consequences at the domestic level, we focus on the political repercussions of the role of PTAs in reducing uncertainty. Trade agreements are commonly understood to clearly define the upper bounds on binding tariff rates. As a result of a PTA, a country's trade regime is simplified and policy-uncertainty is reduced. When policymaking becomes more predictable, domestic economic agents make better and more efficient investment and resource allocation decisions. Reduced uncertainty improves economic performance, strengthening the sitting government's hold on office.

The potential advantages conveyed by signing a PTA vary with a country's regime type. Reduced policy uncertainty benefits incumbent governments to the extent that it raises citizen welfare and thus boosts their probability of remaining in office. The benefits of a PTA are thus highest when government survival depends most heavily on broad citizen approval. The effect of signing a PTA is accentuated by the degree to which the leadership is accountable to the electorate - the degree of democracy.

We present a formal model of the interaction between a leader and her polity. The leader is motivated by a desire for survival in office and trades off the electoral gains from reduced policy volatility with losses in special interest contributions (or other rents) associated with credible trade policy commitments. In such a situation, the number of PTAs signed by a state rises in the degree of electoral accountability. This effect is conditional on country regime-type. We find substantial evidence in support of these claims using empirical tests which establish that (1) the duration of leadership survival increases in PTA formation and (2) that this effect is conditional on the level of 
democracy.

We are not the first to stress the role of uncertainty in determining trade policy. Economists have noted that trade policies may be optimally manipulated to shield firms from unpredictable price movements (see, for instance Eaton and Grossman, 1985). ${ }^{1}$ Nor are we the first to suggest the role of PTAs in reducing policy uncertainty. Scholars of international law often cite the role of the WTO's dispute resolution mechanism in reducing policy uncertainty. For instance, Jackson (2004, 116) argues that the "most important 'central element' of the policy purposes of [the WTO Charter is] ... 'providing security and predictability to the multilateral trading system." Baldwin (1994, 177) notes that "international commerce is promoted by reductions in the uncertainty over future trade and investment policies as well as by increases in the transparency of current policies" - and further suggests that PTAs serve this purpose. However, we are - to the best of our knowledge - the first to suggest that the political benefits of reductions in uncertainty promote incumbents' survival in office. Moreover, we stress that these political benefits vary systematically with regime type a prediction grounded in simple formal model. Finally, we empirically test these novel theoretical implications and find robust support for our predictions.

\section{PTA Formation}

PTAs are agreements by states to limit their trade barriers to levels below some agreed "bound" rates, across a number of sectors and industries. Traditional accounts of PTA formation have relied on income distributional arguments, either within or across countries. PTAs, it has been argued, tie the hands of policy-makers with ex post incentives to protect special interests, or they specify focal points in multiple equilibria scenarios supported by repeated play. ${ }^{2}$ While international political determinants have been extensively studied; ${ }^{3}$ our emphasis here is on the domestic political determinants of PTA formation, particularly on the role of a country's regime-type in shaping its incentives to enter a PTA. Scholars have borrowed from the democratic peace literature, arguing that democracies fight fewer trade wars with each other and are more cooperative on trade issues generally. Regime type explains the willingness to sign PTAs (Mansfield, Milner and Rosendorff, 2000; Pahre, 2008) and the observed heterogeneity in PTA structure and institutional design (Pevehouse, Hafner-Burton and Zierler, 2002). Explanations for the democratic tendency to sign PTAs have re- 
lied on claims about domestic institutional structure. Mansfield, Milner and Rosendorff (2002) for instance suggest that domestic ratification by a protectionist legislature results in more significant bilateral liberalization than occurs in states without a domestic ratification requirement. Milner and Rosendorff (1997) argue that divided government makes international the signing of trade agreements less frequent, but those agreements that are signed bring about greater liberalization than would be the case under unified government. These studies highlight the important role of domestic political and institutional determinants in developing a coherent understanding of PTA formation. In what follows, we contribute to this understanding by changing the angle in which PTAs are viewed, focussing on the effects of PTAs on reducing policy uncertainty. Combining this feature of PTAs with variations in domestic political institutions leads to insights as to the important determinants of leadership survival. Moreover we help to fill the gap as to exactly how domestic institutions might affect PTA signing.

\section{Policy Uncertainty and PTAs}

PTAs serve to limit the policy discretion of signatory governments. They clearly specify the upper bounds on permissible tariffs, the instruments that are available, and the rules and procedures for changing those bounds - reducing the government's ability to alter trade policy.

The government's commitment to reduce trade policy volatility is credible because of the role of PTAs in creating "fire alarms." If a state violates its obligations, the other signatory states, or the PTA institution itself, may alert the violating state and its public that a violation has been alleged. In the case of a finding by a dispute settlement mechanism, the PTA institution may notify the pubic that a violation has occurred. The government faces potential costs from so-violating its treaty commitments, both in the realm of public opinion and due to the danger of retaliation. ${ }^{4}$

A PTA thus offers the opportunity for the policymaker to credibly commit, not only to the level of trade barriers, but to limits over the variability of trade policy. We argue theoretically that the reduced trade policy uncertainty has electoral benefits that are enhanced in democracies; and then we establish empirically that accession to a PTA does in fact enhance leadership survival.

It is worth noting that we focus on the role of PTAs in reducing policy uncertainty, rather than the more traditional emphasis on the distributional consequences of PTAs. We do not dispute that 
PTAs have distributional consequences - and that these consequences have political implications. The precise nature of the distributional effects of PTA formation will depend on the rules of the PTA, factor prices in each member country, and the mobility of the factors of production across sectors of the economy. But, regardless of the distributional consequences of PTA formation, any given PTA will serve to reduce policy uncertainty, and this will have political effects.

A reduction in trade-policy uncertainty increases the volume of trade, and generates gains to voters through the expansion of tradable sectors and the increase in demand for abundant factors in the economy. Mansfield and Reinhardt (2008) argue comprehensively that PTA membership reduces trade policy-uncertainty and boosts trade levels, and they find empirical support for these assertions. ${ }^{5}$ PTAs constrain member states from introducing new trade barriers, they foster policy transparency and convergence in expectations, standards, and policy instruments; and they shift the structure of markets in ways that promote greater stability in commercial transactions over time.

For example, the Asia Pacific Economic Cooperation (APEC) countries focussed specifically on simplification and predictability in its 2001 Principles on Trade Facilitation:

"Consistency and Predictability: Rules and procedures relating to trade should be applied in a consistent, predictable and uniform manner with integrity so as to minimize uncertainty to the trade and trade related parties. ..."

The conclusion we draw is that an executive that has committed to a PTA has enhanced the degree of certainty over trade policy. These institutions clarify obligations, resolve disputes, coordinate policy changes, all of which reduce the public's uncertainty over trade policy.

PTAs also reduce trading partners' ability to manipulate their trade regimes. They therefore reduce the degree of uncertainty faced by exporters, and exporter well-being matters for domestic political support. Mansfield and Reinhardt (2008, 637) offer a number of examples:

"Australia's trade minister acknowledged in 2001 that a chief motivation for establishing the US-Australian FTA was to create an "insurance policy" that limited the possibility of increases in US trade barriers. Facing a proliferation of unfair trade actions initiated by the United States, Canada had a similar objective in forming its free trade agreement with the United States. Chile's agreement with Mercosur was also designed 
to secure its existing level of market access in the Southern Cone. Likewise, a central reason for China's desire to join the WTO was to guarantee access to the US market; heretofore, the extent of this access had been subject to annual and highly politicized congressional reviews. States thus view trade institutions as devices to secure their existing access to their partners' markets, even if additional access is not forthcoming"

PTAs also coordinate member policies, reducing private sector uncertainty over policy outcomes. They thereby improve investment and consumption decisions and reduce the need to self-insure. For instance, the roots of the EU lie in the European Coal and Steel Community, which helped to alleviate the dangers of a potential 'holdup' problem between the coal and steel industries in Germany and France. Absent such an agreement, the threat of the holdup problem would have led steel manufacturers in France to underinvest. ${ }^{6}$ A Brazilian-Argentinian automotive trade pact that was incorporated into Mercosur during the 1990s introduced policy predictability while maintaining highly managed trade. Between 1994 and 2000, imports from one partner to the other were duty free, so long as the importer would export goods of equal value (to any destination). Though it hardly created a liberal tariff regime, the reduction in policy uncertainty as a result of this policy was at least partially responsible for a large increase in the automotive trade between the two countries during that period (MERCOSUR: Objectives and Achievements, 1997).

\section{Reduced Uncertainty Has Welfare and Political Effects}

Reduced uncertainty in trade policy has important welfare-enhancing, and hence political consequences. The reduction in policy uncertainty following the signing of a PTA allows private sector agents to better forecast future policy. This reduced uncertainty increases efficiency by reducing the need to self-insure against policy risk.

Domestic agents value the enhanced policy certainty generated by PTAs. ${ }^{7}$ Previous results conclusively demonstrate that the majority of market participants are risk-averse with respect to policy uncertainty. $^{8}$ van Wijnbergen (1992) shows that trade policy uncertainty distorts private investment and saving decisions that reduce economic efficiency. Abbott (2000) argues in the context of the NAFTA that trade agreements, at least those with "hard law," are adopted to reduce risk premia for private traders and investors. 
Despite the Pareto improvements brought about by a reduction in uncertainty, governments cannot credibly commit to a stable long-term trade policy absent some form of PTA. As Downs and Rocke (1995) and Rosendorff (2005) note, there is stochastic variation in the demands placed on government for trade restrictions. Interest groups, when faced with stochastic shocks, lobby the government for trade protections to alleviate poor market outcomes. Absent a PTA, the government may be inclined to cater to these interests if the value of their contributions outweighs the political costs to reducing trade. The tendency of both home and foreign governments to cater to such interest groups increases the volatility in trade policies faced by importers and exporters and reduces their ability to predict future prices. A PTA, however, reduces this uncertainty, as it (1) commits member governments to clear policy targets, and (2) enforces these targets with policy sanctions. While some uncertainty over trade policy remains, the level of uncertainty is much reduced.

More stable domestic prices enhance economic cooperation, present opportunities for enhanced commercial interaction, and increase the available gains to be had from more predictable trade. Enhanced stability reduces the costs to workers of unexpected unemployment and uncertain wages. Producers in the tradables sectors prefer predictability (Frieden, 2002) and firms are better able to make investment and other allocation decisions in an environment of less uncertainty.

Workers and firms are subject to less uncertainty, and social welfare is enhanced by joining a PTA. Ceteris paribus, we expect this to be translated into political support for leaders that accede to these international institutions. This enhanced political support will, in democracies at least, be translated into higher rates of political survival for those executives that sign PTAs. In the next section we build a theoretical model that links reduced trade-policy uncertainty with leadership survival. We then subject the claim that PTAs increase the probability of government survival - and that this effect is particularly large in democracies - to empirical testing.

The salutary effect of reduced uncertainty may be offset - for a subset of workers and firms - by the distributional consequences of the PTA. Depending on the precise nature of the rules of the PTA, the factor prices in each member country, and the inter-sectoral mobility of the factors of production, certain workers and firms will benefit and others will be harmed as a consequence of PTA formation. But regardless of the distributional consequences, the formation of a PTA will reduce policy uncertainty. Since leaders are unlikely to enter into agreements with such negative distributional consequences that their survival will be harmed, the positive effect of PTA formation 
is expected to dominate. ${ }^{9}$ Our account is thus complementary to (and not a substitute for) those that focus on the distributional consequences of PTA formation.

\section{Model}

Let $t$ be a policy - perhaps a tariff, or a trade rule or regulation. This may be given by the current trade regime in effect, or the rules and regulations associated with a particular preferential trade arrangement. We can think of $t$ as the current policy stance of the government. The state of the current policy regime $t$ is known only imperfectly to the voters in a manner to be made precise below.

\section{Voters}

Let there be a continuum of voters, indexed $i$ on the unit interval $[0,1]$. Each voter $i$ chooses a vector of actions $a_{i}$, and denote the profile of actions for all voters as $a$. Each voter $i$ has a loss function $u_{i}\left(a_{i}, t\right)=-\left(a_{i}-t\right)^{2} \cdot{ }^{10}$ That is, the voters desire to match their actions as closely as possible to match the state of the regulatory environment. For instance if a worker/voter must choose a sector or an industry in which to seek employment, or a capital owner must choose a sector in which to invest, the amount of labor/capital they provide will depend on the expected wage/return on capital, which in turn may depend on the tariff applied to imports in that sector. Or a firm in an industry must adapt its product to match current rules on local content/health and safety, etc. in order to successfully sell its product in the domestic market or in the preferential trading area.

The voter is imperfectly informed about the policy stance, $t$, that will apply. Each voter receives the same public signal $y$ about the likely policy regime with $y=t+\eta$, where $\eta$ is distributed normally with mean zero and variance $\sigma^{2}$. It will be useful to denote the "precision" of the signal as $\alpha=\frac{1}{\sigma^{2}}$. In expectation, therefore, the voter prefers signals that are more precise - which maps to the idea above that individual, and hence social welfare is enhanced by a more stable, or less unpredictable trade policy. 


\section{Executive}

Social welfare is the average utility (which is the same as the total utility) of all voters. $W(a, t)=$ $C-\int_{0}^{1}\left(a_{i}-t\right)^{2} d i$, where $C$ is some arbitrarily large positive real number, $C \gg 0$. Since the maximal value of $-\int_{0}^{1}\left(a_{i}-t\right)^{2}$ is zero, $W$ takes a maximal value at $C$ when the voters are perfectly informed as to government policy. The government however cares about survival in office. Assume for a moment that there is an election, and the probability of reelecting the incumbent is rising in the social welfare. Let $\operatorname{Pr}\{$ reelection $\}=P(W(a, t))$ with $P^{\prime}>0$ and $P^{\prime \prime}<0 . P(W(a, t))$ is therefore a measure of the "will of the voters". We assume that the probability of reelection takes the exponential distribution: $P(x)=1-e^{-\beta x}$ for any $x>0$ and some parameter $\beta>0 .{ }^{11}$

However, the degree to which the will of the voters determines whether or not the incumbent returns to office depends on the regime type, and in particular on the degree to which the holder of office is bound by the interests of the electorate at large. Let $\Delta \in[0,1]$ be a measure of the degree to which the will of the voters is in fact binding on the executive. This will be our measure of the polity's degree of electoral accountability, with $\Delta=1$ suggesting a pure democracy, where the will of the voters is perfectly reflected in the incumbent's probability of reelection. If instead $\Delta=0$, we have a pure autocracy, and the will of the voters is irrelevant to whether or not the incumbent survives in office. Then $\operatorname{Pr}\{$ survival $\}=\Delta P(W(a, t))+(1-\Delta)$. We have a continuous measure of the degree to which the executive is accountable to the voters' sentiments.

While the government benefits from improving electoral prospects by agreeing to sign a PTA, it also sacrifices the ability to manipulate trade policy in response to unforeseen contingencies. As noted above, PTAs help to mitigate a commitment problem. Stochastic shocks to domestic interests may - absent a trade agreement - induce greater lobbying for changes in trade policy (hence $\eta$ may be thought of as a realization of such shocks). Absent a PTA, the government may give in to lobbyists' pressure following such a shock (Dixit, 1996; Downs and Rocke, 1995; Rosendorff, 2005). The inability to respond to lobbyists' demands entails a cost for the government, at least in terms of sacrificed contributions.

We capture the government's choice between increasing policy stability and catering to lobbyists in the following reduced form manner. The government is assumed to derive benefits $R$ from being retained in office, which occurs with probability $\operatorname{Pr}\{$ survival $\}$. It suffers a cost from precision 
$-\frac{1}{2} \alpha^{2}$ that is increasing and convex in $\alpha$. This cost reflects the government's reduced ability to respond to changing interest group demands while in office and its resultant loss of benefits from lobbying activities. The government's utility function is thus given by

$$
G(a, t, \alpha)=\left[\Delta P(W(a, t)+(1-\Delta)] R-\frac{1}{2} \alpha^{2} .\right.
$$

and

$$
u_{i}\left(a_{i}, t\right)=-\left(a_{i}-t\right)^{2}
$$

with

$$
y=t+\eta, \eta \sim N\left(0, \sigma^{2}\right)
$$

\section{PTAs and Uncertainty}

Consistent with the literature discussed above, we assume that PTAs increase precision or reduce the variance of the signal $\sigma^{2}{ }^{12}$ PTAs reduce the variance of uncertain tariff levels. If $\alpha$ is the precision of the signal, we assume that any PTA increases $\alpha$. Moreover each PTA signed has a cumulative effect on overall precision of the signal. If $n$ PTAs are signed, the precision of the signal is $\alpha=\alpha(n)$ with $\alpha^{\prime}>0, \alpha^{\prime \prime}<0$, and $\alpha(0)>0$. We have in mind the idea that a PTA with one state reduces uncertainty with respect to the industries and issues demarcated in the agreement. When negotiating an agreement with a second state, additional sectors and/or industries become subject to the rules-based system. The effect of the second agreement is to at least reduce uncertainty, improve predictability and precision to levels no worse than applied under the first agreement alone. However the marginal effect of the second agreement on overall precision is likely to be less than the first alone. ${ }^{13}$

The number of PTAs signed will be the choice variable for the executive.

Note that we do not model the explicit choice the government faces over the trade policy, $t$. On the one hand, it doesn't really matter here what the policy is to the voters, as long as they can match their behavior to the policy environment. We have, therefore, abstracted away from the distributional consequences of trade policy - which has been studied extensively in this context (see, for instance, Mansfield, Milner and Rosendorff, 2002), in order to focus on the role a PTA plays in coordinating expectations. On the other hand, suppose, as in Mansfield, Milner and 
Rosendorff (2002), there is a domestic policy shock affecting the severity with which the import competing firms pressure the policymaker for trade relief, and this political influence or pressure is unobserved by the voters. Then the policymaker may (or may not) adjust the tariff, even within the permitted parameters of any trade agreement, to accommodate these pressures. Then $t$ is fundamentally unknown to the voters, but they still receive a noisy signal. What matters is the precision of that signal. In order to keep the model simple and tractable, we set aside the game between competing groups over the trade policy itself, and model the consequences of improved precision in the information flows over trade policy.

\section{The Game}

The voter will choose an action $a_{i}$; the executive will decide how many PTA's to sign, $n$. A Bayesian Nash equilibrium (Fudenberg and Tirole, 1991) to this game is a pair of strategies $\left(a_{i}, n\right)$ such that the executive and any voter $i$ is playing a best response. The government, in choosing the number of PTAs to sign, is choosing an optimal level of precision that trades off the welfare gains to the voters (and hence enhanced survival probabilities) with the losses associated with the inability to use opaque practices for the benefit of the themselves of their cronies.

Consider the voter's problem. Taking $n$ as given and hence $\alpha(n)$ as given. The voter receives signal $y$ and maximizes their expected utility:

$$
E u_{i}\left(a_{i}, t \mid y\right)=-a_{i}^{2}+2 a_{i} E(t \mid y)-E\left(t^{2} \mid y\right)
$$

The first order condition yields

$$
a_{i}=E(t \mid y)=y
$$

The executive's problem is to maximize $E G(a, t, \alpha)$ given the voter's optimizing behavior $a_{i}=$ $E(t \mid y)=y$, and the fact that the voter will receive a stochastic signal. The degree of error in the signal, $\eta$, is unknown ex ante. Now $W(a, t)=C-\int_{0}^{1}\left(a_{i}-t\right)^{2} d i$. In equilibrium, $W(a, t)=$ $C-\int_{0}^{1}(y-t)^{2} d i=C-\int_{0}^{1} \eta^{2} d i=C-\eta^{2}$. Then $E G(a, t, \alpha)=\Delta R E P\left(C-\eta^{2}\right)+(1-\Delta) R-\frac{1}{2} \alpha^{2}$.

Notice immediately the trade-off the executive faces: higher precision will mean a higher probability of reelection $E P\left(C-\eta^{2}\right)$ since the expected value of the probability of reelection rises in 
the accuracy of the signal; but more precision means more losses from the executive's dislike of precision, $-\frac{1}{2} \alpha^{2}$.

\section{Results}

We specify the Bayesian Nash equilibrium to the game, and develop a number of testable implications from the model. All proofs are in the appendix.

Proposition 1. The Bayesian Nash equilibrium is $\left(y, \alpha^{-1}\left[\beta+\sqrt{\beta^{2}+\left(R \Delta \beta e^{-C \beta}\right)^{\frac{2}{3}}}\right]\right)$

The voters make their best guess about the policy that is in effect, using the information provided by the public signal, and choose their actions based on that best guess. The government anticipates the voters' behavior, and chooses a level of policy uncertainty (by signing the optimal number of trade agreements) that balances their survival in office with their dislike of policy commitments. Note that the optimal number of PTAs will be a function of the degree of electoral accountability, $\Delta$, as well as the benefits of holding office $R$, and the other parameters of the model, $\beta$ and $C$.

The first two results address the the determinants of the number of PTAs that a leader, concerned with both survival in office and the opportunities for rent creation, will choose to sign. The number of PTAs signed optimally rises with democracy and with the value of the rents from office-holding.

Proposition 2. The equilibrium number of PTAs, $n$ (and the precision $\alpha$ ) rise with democracy, $\Delta$.

Our first result is that the stronger is the degree to which the voters influence leaders' survival in office (what we have called "electoral accountability"), the greater is the need for policy certainty for the electorate relative to the needs of flexibility for rent creation. In order to achieve the required level of predictability, more PTAs are signed in equilibrium.

Of course, the greater is the value to the incumbent of retaining office, the larger are the gains from certainty relative to rent creation, and hence the more frequently are PTAs signed - since signing enhances leadership survival for all types where $\Delta>0$.

Proposition 3. $n$ rises with $R$.

Given the equilibrium behavior of the voters and the executive, we know the number of PTAs that will be chosen; this will generate a level of precision, and has welfare implications for the 
voters. Since the probability that the voters reelect the incumbent is a function of their welfare, we can now specify the expected probability of survival by the incumbent in equilibrium. This survival probability will be a function of the key exogenous parameter of interest, the level of democracy and the (endogenous) number of PTAs.

Lemma 1. The expected probability of survival in equilibrium is $E[\operatorname{Pr}\{$ survival $\}]=1-\Delta e^{-\beta C}$ $\left(\frac{1}{1-\frac{2 \beta}{\alpha(n)}}\right)^{\frac{1}{2}}$

This survival probability is our object of central empirical interest. In the proposition below, we establish that in equilibrium, the executive uses the PTAs to mitigate a key problem facing democratic leaders: eviction from office. Democracy, in the form of electoral accountability, adds fundamental uncertainty to the executive's reelection prospects. More democracy (or less autocracy), ceteris paribus, leads to higher probabilities of eviction from office. The effect of democracy on increasing eviction probabilities can be lessened by reducing policy uncertainty, and hence by signing more PTAs.

\section{Proposition 4.}

- For any level of $\Delta$, as $n$ rises (say due to a rise in $R$ ), $\operatorname{Pr}\{$ survival $\}$ rises.

- For any given level of $n$, as $\Delta$ rises, $\operatorname{Pr}\{$ survival $\}$ falls.

Together the parts of Proposition 4 imply that there is an interaction effect of democracy and PTA formation on the leader's survival probability - democracy reduces survival but PTAs increase survival for any level of democracy. In the next section we subject the key claims of the model that PTAs rise with democracy, and survival rises with PTA formation for any level of democracy to empirical test. We find indeed that democracy increases PTA formation; and that leaders are less likely to be evicted from office as they sign more PTAs, and this effect is heightened by democracy.

\section{Empirics}

PTAs lead to less uncertainty over trade policy, which improves the investment and allocation decisions by the voters, leading to welfare and electoral gains. Mansfield and Reinhardt (2008) find 
that PTAs reduce trade volume volatility; while Francois and Martin (2004) demonstrate that tariff bindings in the Uruguay Round reduced tariff rate volatility in the agricultural sector. The claim of Proposition 2, that the number of PTAs signed rises with democracy, is consistent with Mansfield, Milner and Rosendorff (2000). Our empirical tests below examine the implications of Proposition 4, that PTA signings are closely linked to leadership survival, conditioned by regime type. ${ }^{14}$ In order to show that the particular mechanism we have in mind is indeed operative, we rely both on our reduced form tests and on the evidence advanced by the existing literature.

\section{PTA Signings and Leadership Survival}

In this section, we test the hypotheses advanced in Proposition 4 - that the probability with which government $l$ from country $c$ survives in office is rising in the number of PTAs signed - and in Lemma 1 - that the effect of PTA signings is conditioned by the level of democracy in country $c$. We make use of data drawn from Baccini's database on PTA formation and the Archigos (Goemans, 2006) database on leader survival. The unit of observation in our dataset is the leader-year. Our specifications test whether the hazard rate faced by leader $l$ from country $c$ in year $t\left(h_{l, c}(t)\right)$ is

decreasing in the number of PTAs signed by leader $l,\left(\frac{\partial h_{l, c}(t)}{\partial n_{l}}<0\right)$ and whether this effect is greater in democracies than in non-democracies, $\left(\frac{\partial^{2} h_{l, c}(t)}{\partial n_{l} \partial \Delta_{c}}<0\right)$.

\section{Data}

Time, in our dataset, is defined following the Archigos database on leadership survival. We measure the difference between the current date and the date in which a given leader entered office. ${ }^{15}$ The unit of observation is the leader-year, and we observe 113 countries (with 308 leaders) over the 1995-2004 period. The data is both left- and right-censored (Box-Steffensmeier and Jones, 2004) and we adjust for censoring in our estimates. ${ }^{16}$

Our main regressor of interest is the log of the number of PTAs signed by a given leader. Baccini and Dur (2009) have collected the data on PTA signings for all countries between 1995 and 2008. ${ }^{17}$. We recode this data so that the observation is the leader-year. We then construct a count measure (PTAnumber) of the number of PTAs that go into operation between the time a given leader takes office and year $t$. Our preferred measure is the $\log ($ PTAnumber +1$)$. The use of the logarithm of the 
Table 1: Summary Statistics

\begin{tabular}{lccccc}
\hline \hline Variable & Mean & Standard Deviation & Median & Min. & Max \\
PTAnumber & 3.33 & 6.68 & 0 & 0 & 48 \\
Polity2 & 4.57 & 6.00 & 7.00 & -10.0 & 10.0 \\
$\begin{array}{l}\text { GDP per capita } \\
\text { (year 2000 constant US \$) }\end{array}$ & 9540 & 9230 & 5250 & 444 & 36200 \\
$\begin{array}{l}\text { Openness } \\
\left(\frac{\text { exports+imports }}{G D P}\right)\end{array}$ & 79.4 & 49.3 & 70.5 & 14.8 & 462 \\
$\begin{array}{l}\text { Growth } \\
\text { (\% change 2000 constant US \$) }\end{array}$ & 2.18 & 5.49 & 1.96 & -17.2 & 61.5 \\
\hline \hline
\end{tabular}

number of PTAs signed reflects the theoretical claim that the effect of PTAs on policy uncertainty is subject to diminishing marginal returns. ${ }^{18}$

Leaders in the sample vary substantially in the number of PTAs signed. The median leader does not sign a PTA during her tenure in office. However, by 2004, President Mubarak of Egypt, King Muhammad VI of Morocco, and President Ben Ali of Tunisia had all entered into 48 PTAs during their respective times in office. Nineteen leaders, from such diverse countries as Croatia, Mexico, and Chile, sign 30 PTAs during their tenure. Summary statistics are presented in Table 1 below.

Our measure of democracy is taken from the Polity 4 index (2008 version)(Marshall and Jaggers, 2000). ${ }^{19}$ The polity measure consists of a subjective index of the level of democracy (running from 0-10) and autocracy (similarly running from 0-10). We make use of the cumulative democracy score (polity2), which is defined as the democracy index score minus the autocracy index score, and assumes values from -10 to 10 . We also interact this value with the log number of PTAs that come into operation under a given leader, to test the conditional nature of the effect of PTA formation postulated in Lemma $1 .^{20}$

Included as controls are values of real per capita GDP in purchasing power parity terms, the percentage growth rate in real GDP, and the degree of economic openness ( $\frac{\text { Exports+Imports }}{\text { GDP }}$ ). All values are drawn from the Penn World Tables version 6.2 (Heston, Summers and Aten, 2006). A list of summary statistics is provided in Table 1.

We also present summary statistics of the number of PTAs signed per-leader-per-year and per- 
Table 2: Probability of Signing a PTA in a Given Year, by Regime Type

\begin{tabular}{lcc}
\hline \hline Regime Type & Mean PTA Indicator & Standard Dev. \\
\hline Democracy & 0.27 & 0.45 \\
Anocracy & 0.19 & 0.39 \\
Autocracy & 0.19 & 0.39 \\
\hline \hline
\end{tabular}

The probability of signing a PTA in a given year, by regime type. A leaderyear is scored as a democracy if the polity 2 score is greater than or equal to 5 . A leader-year is scored as an autocracy if the polity2 score is less than or equal to -5 . All other leader years are scored as anocracies. To derive this measure, we rely on an indicator variable that is coded as 1 if a given leader signed a PTA in a given year.

leader in Tables 2 and 3, respectively. ${ }^{21}$ We define any regime with a polity2 score of 5 or above as a democracy, any regime with a polity2 score of -5 or below as an autocracy, and all other polity scores as anocracies. As is consistent with theoretical expectations - and with the existing results of Mansfield, Milner and Rosendorff (2000) - democratic governments are more likely to sign a PTA in any given year than are autocratic governments. This simple difference-in-means is significant at a 95 percent level when using a two-tailed p-text $(p=.03)$. However, autocratic leaders, on average, sign more PTAs during their tenure in office - largely due to their longer average survival times.

To test our central hypothesis, we adopt two alternative estimation procedures. In the first, we estimate a Cox frailty proportional hazards model, to assess the effect of PTA formation and democracy on the expected rate of regime failure across leaders. We find strong support for the theoretical claims above using this approach. The specification however, is open to the criticism of selection bias - countries/leaders that accede to PTAs may be self-selecting based on some observable or non-observable dimensions. To deal with resultant problems of covariate balance, we adopt a second estimation procedure that pre-processes the data in order to match signers with non-signers via propensity score matching. In both specifications, the data offers substantial support for the theoretical claims.

\section{Cox Frailty Model Estimates}

To investigate the effect of PTA signings on leader survival, we estimate a Cox proportional hazards model. The semi-parametric Cox model estimates the hazard rate of leader $l$ as a function of a baseline hazard function $h_{0}(t)$ and observed covariates, $\mathbf{X}_{\mathbf{l , c}}: h_{l, c}(t)=h_{0}(t) e^{\mathbf{X}_{l, c} \gamma+\epsilon_{l, c}}$. The 
Table 3: Ave. Num. of PTAs Signed by a Given Leader, by Regime Type

\begin{tabular}{lcccc}
\hline \hline Regime Type & Mean Num. PTAs & Standard Dev. & Min & Max \\
Democracy & 2.90 & 5.73 & 0 & 40 \\
Anocracy & 4.24 & 8.98 & 0 & 48 \\
Autocracy & 11.83 & 14.1 & 0 & 48 \\
\hline \hline
\end{tabular}

The total number of PTAs signed by a given leader, by regime type. A leader is scored as democratic if her average polity2 score over the period is greater than or equal to 5 . A leader is scored as autocratic if her average polity2 score over the period is less than or equal to -5 . All other leaders are scored as heading anocracies. We report the total number of PTAs signed by each leader in the period.

baseline hazard function is estimated non-parametrically using the observed time of regime failure. The hazard function is not constrained to take on any particular functional form. Time is, therefore, effectively treated as a nuisance parameter (Box-Steffensmeier and Jones, 2004).

Differences in covariate values shift the baseline hazard function up or down. Positive coefficient values imply that an increase in a given variable is associated with an upwards shift in the hazard function - i.e. that a leader faces a greater risk of removal as the covariate increases. Negative coefficient values imply the reverse. ${ }^{22}$ Results from a Cox frailty model regressing leadership survival on the log number of PTA signings are reported as Models 2 and 4 in Table 4.

In our estimates, we adjust for the shared frailty faced by regimes from a given country. That is, we assume the survival times of regimes from the same country are correlated. As a result, some regimes will be more prone to failure - more frail - than others. We therefore estimate a model $h_{l, c}(t)=h_{0}(t) e^{\mathbf{X}_{l, c} \gamma+\theta_{c}+\epsilon_{l, c}}$ where $\theta_{c}$ is a country-specific frailty parameter drawn from a log-Gamma distribution with mean zero. This is equivalent to estimating model with countryspecific random effects in a more standard time-series-cross-section framework (Box-Steffensmeier and Jones, 2004).

The basic Cox frailty model makes no assumption about the shape of the baseline hazard function $h_{0}(t)$, but it does assume that hazard rates are proportional across units - i.e. that changes in covariate values shift the hazard function up or down, but do not affect its shape. We test these assumptions using Grambsch-Therneau and Harrell's rho tests. ${ }^{23}$ Both the Grambsch-Therneau global test and the covariate specific Harrell's rho test reject the proportional hazards assumption. ${ }^{24}$ The values of the log number of PTAs signed and Polity scores appear to both shift the hazard function and affect its shape. We control for this effect by including the interaction of these terms with sur- 
vival time (defined as the number of years in office) (Box-Steffensmeier and Jones, 2004). Results from these specifications are reported as Models 1 and 3 in Table 4.

In the coefficient estimates reported in Table 4, the sign on the log number of PTAs signed under a given regime is negative in all specifications. In words, as the number of PTAs signed increases, the hazard rate faced by a given leader declines - i.e. her probability of survival increases. These results indicate that the number of PTAs is associated with longer survival times in both specifications (reduced failure rates) - as is consistent with Proposition 4. The estimates in Models 1 and 3 reveal that this effect is not constant over time in office - the effect of signing PTAs decreases for leaders that have long served in office relative to those that are new to their post. ${ }^{25}$ The association between PTA signings and leadership survival goes to zero for leaders that have been in office for between 10 and 15 years. This diminishing effect is intuitively consistent with our policy-uncertainty story - as leaders serve longer in office, private sector agents can better predict policy changes based on past behavior. Thus, the effects of PTA signings on the misallocation of resources diminish over time.

The coefficient estimate on the Polity measure of democracy is positive in both specifications. Increasing levels of democracy - as measured by the Polity index - are associated with reduced leadership survival times. This finding is also consistent with Proposition 4. The association between Polity scores and risk of removal is shown to be increasing over time in Models 1 and 3.

Lemma 1 predicts that the coefficient on the interaction between Polity scores and the $\log$ number of PTA signings will be negative. In words, we predict that the relationship between PTA signings and regime longevity is stronger in democracies than in non-democracies. All non-linear models allow for some interactive effect between the parameters, since the likelihood function is not additively separable in the parameters. We allow for greater flexibility in the estimation of the conditional relationship between PTA signing and leadership survival by including an interaction term between the number of PTAs signed and the polity score in our model specification (Berry, DeMeritt and Esarey, 2010; Nagler, 1991)

The point estimate on the interaction between PTA signings and the polity score is negative in Model 2, but it is positive in Model 1. In neither is it significant. However, considerable caution must be used in interpreting interaction effects in non-linear models (Ai and Norton, 2003; Berry, DeMeritt and Esarey, 2010; Greene, 2010). A significant coefficient estimate on an interaction 
Table 4: Cox-Frailty Proportional Hazards Estimates

\begin{tabular}{|c|c|c|c|c|}
\hline & Model 1 & Model 2 & Model 3 & Model 4 \\
\hline $\begin{array}{l}\text { Main Regressors } \\
\text { Log(PTAnumber) }\end{array}$ & $\begin{array}{l}-0.687 * * \\
(0.281)\end{array}$ & $\begin{array}{l}-0.279 * \\
(0.157)\end{array}$ & $\begin{array}{c}-0.652 * * * \\
(0.153)\end{array}$ & $\begin{array}{c}-0.386 * * * \\
(0.107)\end{array}$ \\
\hline Polity2 & $\begin{array}{l}0.0721 * \\
(0.0382)\end{array}$ & $\begin{array}{l}0.152 * * * \\
(0.0320)\end{array}$ & $\begin{array}{l}0.0706 * \\
(0.0364)\end{array}$ & $\begin{array}{l}0.142 * * * \\
(0.0293)\end{array}$ \\
\hline Log(PTAnumber)*Polity2 & $\begin{array}{l}0.000395 \\
(0.0336)\end{array}$ & $\begin{array}{l}-0.0173 \\
(0.0195)\end{array}$ & & \\
\hline GDP per capita & $\begin{array}{l}-0.0000102 \\
(0.0000129)\end{array}$ & $\begin{array}{l}-0.0000145 \\
(0.0000128)\end{array}$ & $\begin{array}{l}-0.0000100 \\
(0.0000129)\end{array}$ & $\begin{array}{l}-0.0000149 \\
(0.0000129)\end{array}$ \\
\hline Openness & $\begin{array}{l}-0.00245 \\
(0.00249)\end{array}$ & $\begin{array}{l}-0.00231 \\
(0.00247)\end{array}$ & $\begin{array}{l}-0.00243 \\
(0.00249)\end{array}$ & $\begin{array}{l}-0.00219 \\
(0.00249)\end{array}$ \\
\hline Growth & $\begin{array}{l}-0.00745 \\
(0.0159)\end{array}$ & $\begin{array}{l}-0.00624 \\
(0.0159)\end{array}$ & $\begin{array}{l}-0.00754 \\
(0.0159)\end{array}$ & $\begin{array}{l}-0.00659 \\
(0.0159)\end{array}$ \\
\hline $\begin{array}{l}\text { Time Varying Regressors } \\
\text { Log(PTAnumber) }\end{array}$ & $\begin{array}{l}0.0501 * * \\
(0.0222)\end{array}$ & & $\begin{array}{l}0.0472 * * \\
(0.0191)\end{array}$ & \\
\hline Polity2 & $\begin{array}{l}0.0105^{*} \\
(0.00559)\end{array}$ & & $\begin{array}{l}0.0116 * * \\
(0.00472)\end{array}$ & \\
\hline Log(PTAnumber)*Polity2 & $\begin{array}{l}0.000892 \\
(0.00323)\end{array}$ & & & \\
\hline Num. of Subjects & 308 & 308 & 308 & 308 \\
\hline Num. of Failures & 197 & 197 & 197 & 197 \\
\hline $\begin{array}{l}\text { Frailty Parameter } \\
\text { p-value }\end{array}$ & $\begin{array}{c}\chi^{2}=14.50 \\
0.00\end{array}$ & $\begin{array}{c}\chi^{2}=14.55 \\
0.00\end{array}$ & $\begin{array}{c}\chi^{2}=14.79 \\
0.00\end{array}$ & $\begin{array}{c}\chi^{2}=14.37 \\
0.00\end{array}$ \\
\hline
\end{tabular}

Results from a Cox proportional hazards regression of leadership survival times on the log number of PTA signings, Polity scores, and controls drawn from the Penn World Tables 6.2. Standard errors are reported in parentheses. ${ }^{* * *}$ implies significance at the 99 percent level, ${ }^{* *}$ implies significance at the 95 percent level, and ${ }^{*}$ implies significance at the 90 percent level. Time varying regressors are interacted with time in office. 
term is "neither a necessary nor sufficient" condition for establishing the existence of an interactive relationship (Berry, DeMeritt and Esarey, 2010, p.25). The preferred method to interpret interactive effects in such models is through the graphical presentation of the relationship between changes in the variables of interest and the outcome measure.

The marginal association between PTA signings and regime survival is illustrated graphically in Figure 1. This figure plots the estimated hazard rates generated by Model 2 in Table 4. The graph to the left depicts the estimated hazard rate when polity2 scores are at their minimum value, -10 . Those to the right display the estimated hazard rates when polity2 is set to its maximum value, +10. Plots in both graphs display the estimated hazard rate when the number of PTAs signed is zero, one, and its maximum value in the sample (48). The figures demonstrate clearly that there is a difference between democracies and autocracies in the effect of signing treaties on survival in office - that democracies benefit from signing treaties more than autocrats.

\section{Problems of Endogenous Selection into Treaties}

In our discussions of our empirical results so far, we have referred to the Cox frailty model above as a first estimate of the effect of PTA signings on leader survival. It could be argued that our estimates fail to adjust for the endogenous selection of regimes into treaties. Since these estimates fail to adjust for this endogenous selection, they potentially produce a biased estimate of the effect of PTA signings. Moreover, even assuming the results are unbiased, they are heavily dependent on modeling assumptions. (Morgan and Winship, 2007; Simmons and Hopkins, 2005; von Stein, 2005).

Assume that a government's decision of the number of PTAs to sign can be characterized by the function $P T$ Anumber $r_{l, c}=N e g \operatorname{Bin}\left(\mathbf{Z}_{l, c} \beta+\zeta_{l, c}\right)$, where $N e g B i n$ is the negative binomial function. This then implies that regimes that sign a large number of PTAs will be systematically different from regimes that sign few or no PTAs. Even if the regressions above control for all covariates associated with PTA signing (i.e. $\mathbf{Z}_{l, c} \subseteq \mathbf{X}_{l, c}$ ), the estimates of the causal effect of PTA signings will only be unbiased if $\zeta_{l, c}$ is uncorrelated with the error term in the Cox models (i.e. $\operatorname{corr}\left(\epsilon_{l, c}, \zeta_{l, c}\right)=0$ ) (Greene, 2002).

Moreover, the fact that those regimes that sign a large number of PTAs differ systematically on 
Figure 1:

\section{Estimated Hazard Rates}
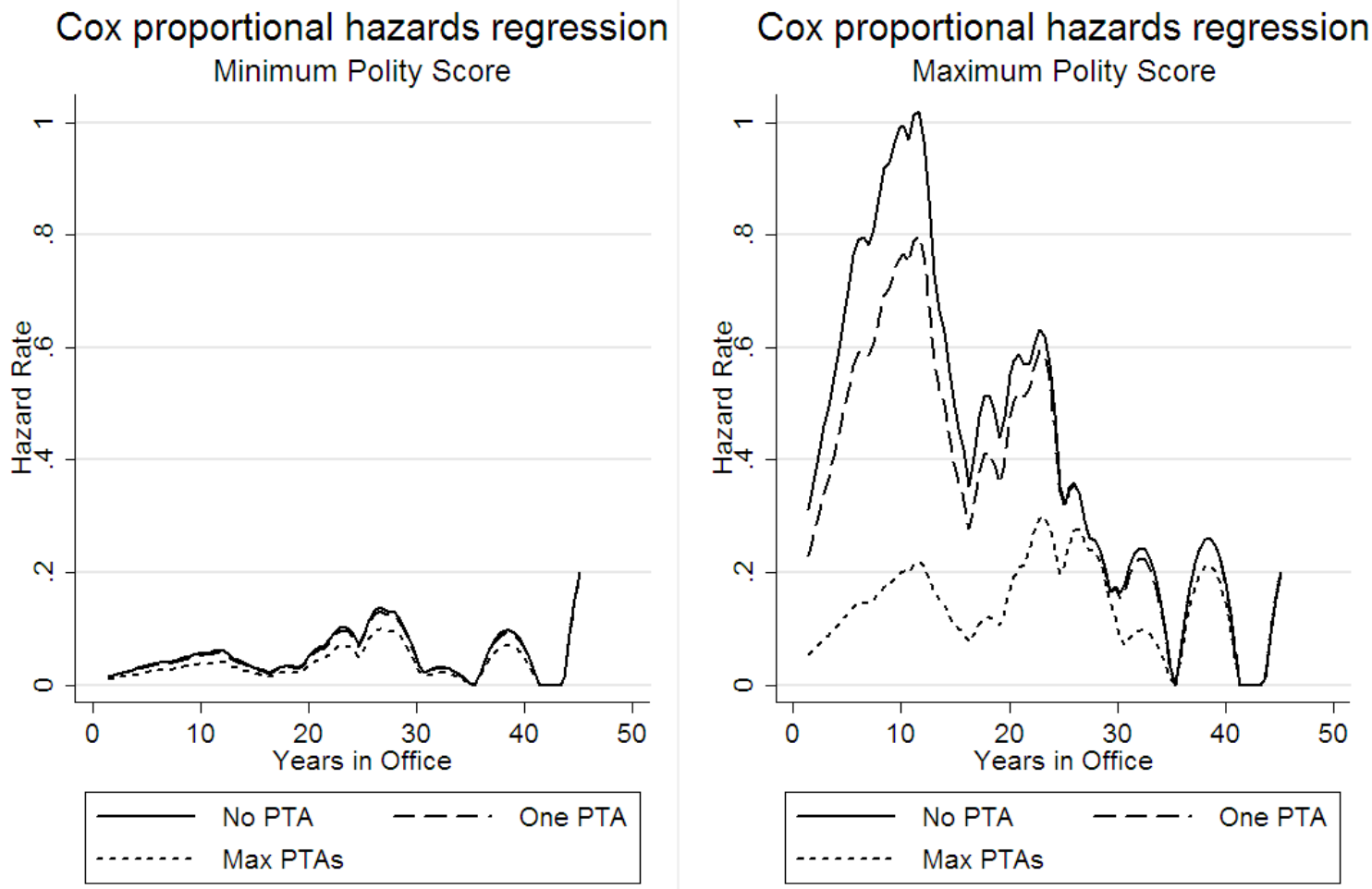

Hazard rate estimates from Model 2 in Table 4. Hazard rates are on the y-axis, years in office is on the $\mathrm{x}$-axis. Estimates in the graph to the left reflect a polity2 score of -10; those on the right reflect a polity 2 score of 10 . The number of PTAs signed by a given leader is equal to 0 for the solid line in both graphs, 1 for the dashed, and 48 for the dotted. All other variables are set to their mean values. 
observed covariates $\left(\mathbf{Z}_{l, c}\right)$ from those that sign few or no PTAs implies that causal estimates are heavily dependent on modeling assumptions. Endogenous selection into treaty signings introduces problems of both covariate balance and covariate overlap. Assume that those regimes that sign large numbers of PTAs are overwhelmingly highly democratic; while those that sign few PTAs are overwhelmingly autocratic. Since we observe few instances of autocratic regimes signing large numbers of PTAs, we must extrapolate from the existing data to adequately construct "control" and "treatment" groups. In a regression context, we accomplish this by relying on our modeling of the data generating process - particularly the assumption that observed covariates shift the hazard rate according to $e^{\mathbf{X}_{1, \mathbf{c}} \gamma+\epsilon_{1, \mathbf{c}}}$ (Gelman and Hill, 2006; Morgan and Winship, 2007). As such, our estimates are likely to be heavily dependent on modeling assumptions.

We can adjust for the potential dangers of selection on observable terms and the resultant model dependence. ${ }^{26}$ Below, we employ propensity score matching to help ensure covariate balance in our sample. If the sample is balanced on observables, our estimates depend less strongly on modeling assumptions and we thus have greater confidence that we are not extrapolating beyond what the data can tell us.

\section{Matching Estimates}

Problems of covariate balance can be mitigated through the use of propensity score matching algorithms (Ho et al., 2007; Morgan and Winship, 2007). These algorithms pair (match) units that enter into "treatment" (i.e. sign a PTA) with similar units that do not. This is accomplished by estimating the probability with which a given unit enters into treatment. Treated units are matched with untreated units that are estimated to have a similar probability of receiving treatment. Units that cannot be so matched are removed ("pruned") from the dataset. As a result, the analyst is left with a dataset of observationally similar treated and non-treated units, reducing the model dependence of any subsequent regression analysis (Ho et al., 2007).

The application of propensity score matching to our dataset is complicated by its panel structure. In essence, the units to be matched are panels not observations - i.e. leaders and not leader-years (Nielsen and Simmons, 2009). To conduct this matching we rely on a procedure first applied by Simmons and Hopkins (2005). For a leader that signs a PTA in year $t$, we average observed covari- 
ates in all years prior to $t$. For all leaders who do not sign a PTA, we average observed covariates for all periods under observation. We are thus left with a dataset where the unit of observation is the leader. We then match leaders who sign a PTA to those that never sign a PTA, pruning all leaders from the dataset for whom no match can be found. The data is then decompressed, so that the unit of observation is once again the leader-year, and the Cox analysis run above is run on the pruned dataset.

We generate our matched dataset using the MatchIt (Ho et al., 2004) package run from $\mathrm{R}$ 2.7.1. We employ a nearest-neighbor matching algorithm with a caliper of 0.5 standard deviations. Matching is conducted without replacement, so each pair consists of a leader who signs a PTA and one who did not do so. In the resultant dataset, 125 PTA signatories are paired with 125 non-signatories. 36 non-signatories and 22 signatories are pruned from the dataset. Graphical diagnostics of the matching procedure, and results from the propensity score equation, are reported in the Appendix.

Results from Cox frailty models run on the matched dataset are reported in Table 2. Models 1-4 are identical to the corresponding Models 1-4 in Table 4. In all models, the coefficient on the respective PTA signing variables is negative - significantly so in all but Model 2. These results are consistent with the estimates in the unmatched Cox model above and with the theory advanced in the previous section. As was also true above, these associations diminish over time in office.

Coefficients on the polity2 score are positive in all specifications and significant wherever time varying covariates are not included. Increasing polity scores are robustly associated with higher hazard rates - implying a greater risk of removal from office. Again, this is consistent with Proposition 4 above. In models with time-varying covariates, we find that the effect of polity scores on the hazard rate increases over time.

When an interaction between the PTA signing term and the polity score is included in the model, the coefficient on this interaction is always negative. The point estimate on this coefficient suggests that the effect of PTA signings on leadership survival is greater in democracies than in non-democracies. Graphical evidence for the conditional nature of the relationship between PTA signings and leadership survival is presented in Figure $2 .^{27}$

We present displays of the predicted hazard rate from Model 2 in Figure 2. The difference in survival rates between democracies and non-democracies is readily visible across the two graphs. 
Table 5: Matched Estimates, Cox-Frailty Model

\begin{tabular}{|c|c|c|c|c|}
\hline & Model 1 & Model 2 & Model 3 & Model 4 \\
\hline Main Regressors & & & & \\
\hline Log(PTAnumber) & $\begin{array}{c}-0.702^{* * *} \\
(0.317)\end{array}$ & $\begin{array}{l}-0.188 \\
(0.166)\end{array}$ & $\begin{array}{c}-0.742^{* * * *} \\
(0.186)\end{array}$ & $\begin{array}{c}-0.345^{* * * *} \\
(0.110)\end{array}$ \\
\hline Polity2 & $\begin{array}{c}0.0635 \\
(0.0427)\end{array}$ & $\begin{array}{l}0.156 * * * \\
(0.0361)\end{array}$ & $\begin{array}{c}0.0628 \\
(0.0396)\end{array}$ & $\begin{array}{l}0.139 * * * \\
(0.0324)\end{array}$ \\
\hline Log(PTAnumber)*Polity2 & $\begin{array}{l}-0.00442 \\
(0.0395)\end{array}$ & $\begin{array}{l}-0.0249 \\
(0.0207)\end{array}$ & & \\
\hline GDP per capita & $\begin{array}{l}-0.0000176 \\
(0.0000133)\end{array}$ & $\begin{array}{l}-0.0000199 \\
(0.0000132)\end{array}$ & $\begin{array}{l}-0.0000178 \\
(0.0000133)\end{array}$ & $\begin{array}{l}-0.0000202 \\
(0.0000133)\end{array}$ \\
\hline Openness & $\begin{array}{l}-0.00253 \\
(0.00283)\end{array}$ & $\begin{array}{l}-0.00246 \\
(0.00279)\end{array}$ & $\begin{array}{l}-0.00252 \\
(0.00283)\end{array}$ & $\begin{array}{l}-0.00236 \\
(0.00278)\end{array}$ \\
\hline Growth & $\begin{array}{l}-0.00991 \\
(0.0193)\end{array}$ & $\begin{array}{l}-0.00959 \\
(0.0195)\end{array}$ & $\begin{array}{l}-0.00991 \\
(0.0193)\end{array}$ & $\begin{array}{l}-0.00976 \\
(0.0195)\end{array}$ \\
\hline $\begin{array}{l}\text { Time Varying Regressors } \\
\text { Log(PTAnumber) }\end{array}$ & $\begin{array}{l}0.0724 * * \\
(0.0325)\end{array}$ & & $\begin{array}{l}0.0737 * * * \\
(0.0282)\end{array}$ & \\
\hline Polity2 & $\begin{array}{l}0.0134^{*} \\
(0.00721)\end{array}$ & & $\begin{array}{l}0.0128 * * \\
(0.00559)\end{array}$ & \\
\hline Log(PTAnumber)*Polity2 & $\begin{array}{l}-0.000141 \\
(0.00476) \\
\end{array}$ & & & \\
\hline Num. of Subjects & 250 & 250 & 250 & 250 \\
\hline Num. of Failures & 158 & 158 & 158 & 158 \\
\hline $\begin{array}{l}\text { Frailty Parameter } \\
\text { p-value }\end{array}$ & $\begin{array}{c}\chi^{2}=5.41 \\
0.010\end{array}$ & $\begin{array}{c}\chi^{2}=5.06 \\
0.012\end{array}$ & $\begin{array}{c}\chi^{2}=5.39 \\
0.010\end{array}$ & $\begin{array}{c}\chi^{2}=4.87 \\
0.014\end{array}$ \\
\hline
\end{tabular}

Results from a Cox proportional hazards regression of leadership survival times on the log number of PTA signings, Polity scores, and controls drawn from the Penn World Tables 6.2. Standard errors are reported in parentheses. ${ }^{* * *}$ implies significance at the 99 percent level, ${ }^{* *}$ implies significance at the 95 percent level, and ${ }^{*}$ implies significance at the 90 percent level. 
Figure 2:
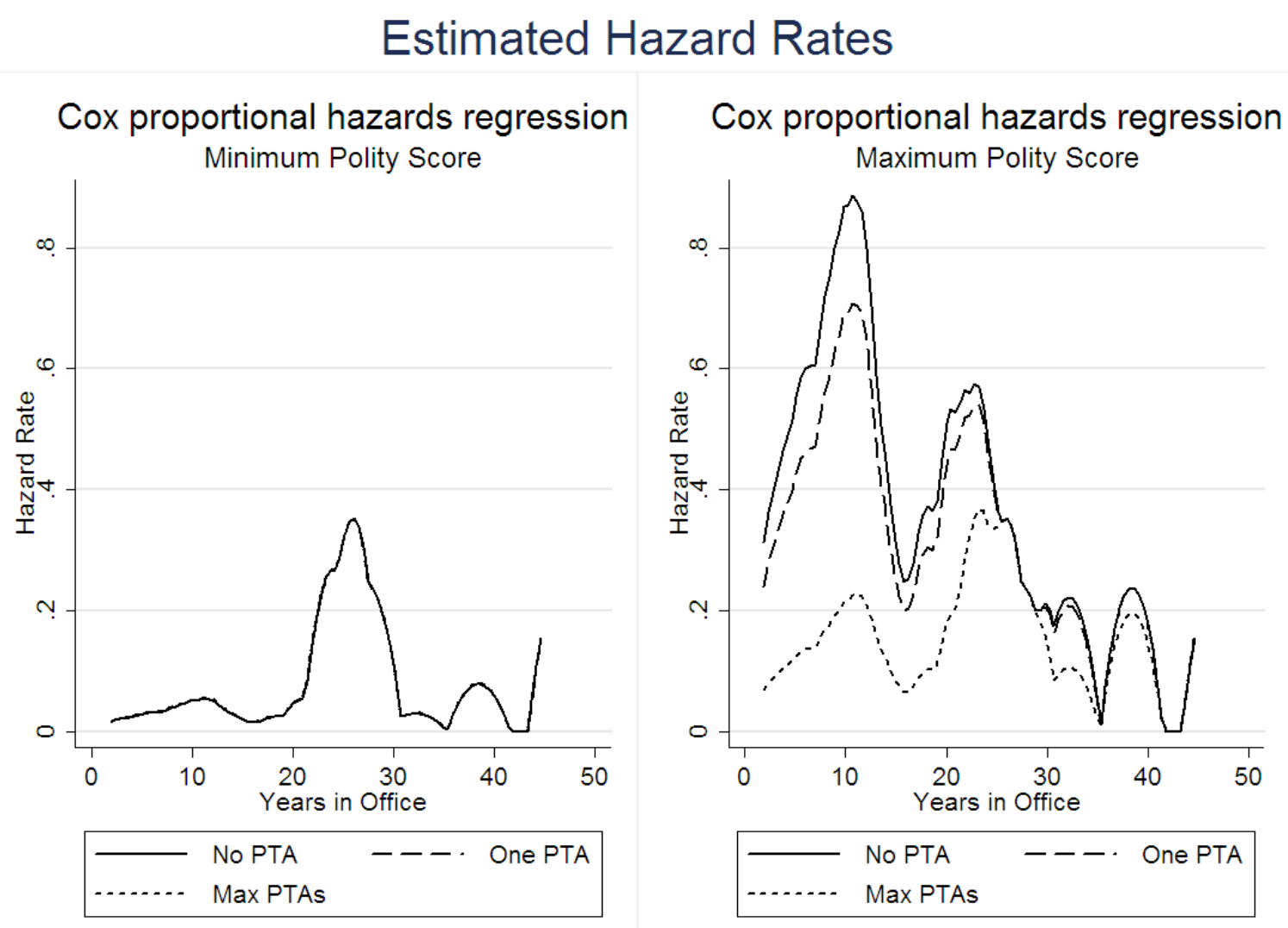

Hazard rate estimates from Model 2 in Table 5. Hazard rates are on the y-axis, years in office is on the x-axis. Estimates in the graph to the left reflect a polity2 score of -10; those on the right reflect a polity2 score of 10 . The number of PTAs signed by a given leader is equal to 0 for the solid line in both graphs, 1 for the dashed, and 48 for the dotted. All other variables are set to their mean values.

The two graphs also make clear that signing a PTA has little effect on the survival of a highly autocratic regime. In highly democratic regimes, however, the effect of PTA signings is clearly visible and quite dramatic. Those democratic leaders that enter into PTAs face substantially lower risks to removal from office.

\section{Conclusion}

We have demonstrated that leaders sign PTAs in order to enhance their prospects of remaining in office, and this is especially true in democracies. In the theory section above we have argued that 
this enhanced probability of survival follows directly from the reduced uncertainty voters face over trade policy associated with PTA signing.

PTAs serve to ground citizens' expectations over government policy. They establish bounds on the range of possible policies the government can implement. As a result of this effect on citizen expectations, PTAs enhance efficiency even if they don't significantly liberalize trading regimes. The resultant gains to citizen welfare have political implications for the incumbent government particularly if that government happens to be a democracy.

These findings are consistent with an established literature that stresses the impact of PTAs on the volatility of trade (Francois and Martin, 2004) and on trader and investor risk (Abbott, 2000). It also builds upon claims that PTAs are a response to a government commitment (time-consistency) problem (Dixit and Londregan, 1995; Mansfield, Milner and Rosendorff, 2002). However, unlike the former accounts, our model examines the political repercussions of a reduction in policy uncertainty. And unlike the latter models, ours focuses on the uncertainty reducing effects of treaties, rather than on their income distributional impact.

Mansfield and Milner (2009) in unpublished work have also explored the links between PTA membership and leadership survival. We view these efforts as complementary, but distinct. Mansfield and Milner claim that democratic leaders sign PTAs to avoid the "negative externalities" associated with protectionism. They suggest that governments can engage in unobservable protectionist deals with special interests that negatively effect other members of the domestic polity. PTAs constitute a commitment mechanism - governments that sign PTAs are assumed to be unable to enter into such side deals, or if they do so the suffer electoral consequences. By contrast, we argue that PTAs reduce the volatility of trade policy. We offer a formal theoretical foundation for our claims regarding the effect of the policy uncertainty on leadership survival, while Mansfield and Milner rely largely on the theoretical foundations of Mansfield, Milner and Rosendorff (2002) and Mansfield, Milner and Pevehouse (2007), neither of which explicitly model leadership survival. ${ }^{28}$

These are the first results that establish that PTA signing enhances leadership survival, and more so in democracies. While previous studies have established that democracies are more likely to sign PTAs (Mansfield, Milner and Rosendorff, 2002), none have studied leadership survival directly. Moreover this previous work has been motivated by theory that prioritizes the credible commitment the PTA offers over the levels of the trade barriers; this paper focusses instead on the credible 
commitment the PTA offers to effectively limit the variability of trade policy.

While we present compelling evidence in support of the central hypotheses, as always these results should be interpreted with appropriate caution. This is not a general theory of leadership survival Bueno de Mesquita et al. (2003, see, for instance); a number of factors that may be relevant have been omitted. For instance, we do not have data on term limits, and we cannot control for the competence of leaders (although growth and openness, control variables we do use, might proxy for competence), among others. Nevertheless, the results offer strong support for the claim that PTAs, by reducing policy uncertainty, increase survival in office, especially in democracies.

Similarly this is not a general theory of PTA accession. We have focussed on the role PTAs play in coordinating expectations. Other mechanisms may be operative: as we have argued, PTAs limit the levels of trade barriers, perhaps enhancing leadership survival in democracies; or a PTA may simply be a signal of the leader's competence, and voters may simply be rewarding competence. Ideally, we would develop empirical tests to distinguish these possible mechanisms. Obtaining data on leader competence, extractive behavior or policy uncertainty across time and countries is of course tricky - these are fundamentally unobservable, and existing data is not reliable.

These findings may extend to other international institutions. Many international agreements - including 'voluntary commitments' that lack formal punishment mechanisms for non-compliance - provide information to domestic audiences regarding the future policy decisions of the government. Three essential elements are necessary for the theoretical mechanisms outlined in this paper to apply: (1) the uncertainty of domestic actors (stemming from a lack of transparency or frequent variation in policies) over their government's policy, (2) a (probabilistic) incentive for the government to change policies in the future such that it cannot commit to stable policies in the present, and (3) the - implicit or explicit - enforcement of any international agreement by other state-parties. When these features are present, the government may use international agreements to anchor domestic expectations, diminishing policy uncertainty and boosting citizen welfare.

The incentives to enter into such an agreement will be determined, in part, by domestic political institutions. Higher levels of democracy lead, ceteris paribus, to greater incentives to boost citizen welfare. As such, democracies have a stronger rationale for entering into international agreements with the aim of reducing policy uncertainty. 


\section{Notes}

${ }^{1}$ However, see the rebuttal of Dixit (1989), who finds that government interventions are sub-optimal when the domestic insurance market is fully modeled.

${ }^{2}$ Economic explanations starting with Johnson (1953) rely on the notion that unilateral "beggar-thy-neighbor" policies result in a reduction in world and societal welfare. Bagwell and Staiger (1999) show that tariff bindings restrict the shifting of rents across borders, and eliminate the terms-of-trade motivation for protection. PTAs increase the size of the domestic market, allowing local firms to achieve economies of scale, and when it comes to trading relations with other groups of states and regions, the increased market power increases a state's negotiating power at the international level (Krugman, 1993). Economic arguments for PTA formation have also been used at the domestic level: trade barriers protect the incomes of certain sectors or domestic factors of production, but create a social externality in that they impose costs on other sectors and factors; trade agreements are said to be binding commitments not to favor special interests at the cost of broader societal welfare (Maggi and Rodriguez-Clare, 1998; Dixit and Londregan, 1995).

${ }^{3}$ PTAs form in reaction to each other (Fernandez and Portes, 1998), or the hegemonic power of the United States (Krugman, 1993; Bhagwati, 2008). They form in the response to the lack of progress at the WTO in achieving further gains from multilateral trade liberalization (Bhagwati, 2008), or they form among alliances for security purposes (Gowa and Mansfield, 1993), or for encouraging changes in policies that are linked to trade, such as human rights (HafnerBurton, 2005), or they are formed in order to increase FDI flows (Tobin and Busch, 2010).

${ }^{4}$ Reporting on the behavior of signatories is often a central function of many commercial agreements. The European Union (EU) issues public summaries of the extent to which countries are adopting and implementing its directives. The North American Free Trade Agreement's (NAFTA's) dispute settlement mechanism serves a similar purpose; countries can be publicly accused of violating their international commitments and forced to undergo a long, open process of defending their behavior.

${ }^{5}$ The claim that a reduction in trade policy uncertainty increases trade levels relies on the assumption that traders are risk-averse. This risk aversion may stem from many causes: incomplete insurance markets, underdeveloped financial markets, etc. The empirical support Mansfield and Reinhardt (2008) find for this assertion supports the claim that the majority of traders are risk averse.

${ }^{6}$ According to Milward (1992), the creation of the ECSC involved an implicit compromise regarding the export of German coal. Prior to the formation of the ECSC, occupied Germany was required to export coal to the European market under the auspices of the Ruhr Authority. The creation of the ECSC allowed for the Ruhr Authority to be phased out of operation while ensuring that German coal exports continued - reassuring steel producers elsewhere in Europe, especially in France.

${ }^{7}$ Policy uncertainty in general generates significant deadweight losses to the economy. Rodrik (1991) shows that uncertainty regarding the policy environment can act as a "hefty" tax on investment especially in developing economies, and has significant consequences for growth. Aizenman and Marion (1993) show that policy uncertainty and growth are correlated. Feng (2001) shows that policy uncertainty adversely effects private investment in developing economies. Leblang and Satyanath (2006) find that divided government and government turnover - factors associated with political 
risk - increase the likelihood of currency crises. Broz (2002) notes that opaque political systems reduce the ability of private agents to forecast policies. For much the same reason we argue governments adopt a PTA, he suggests states adopt pegged currencies. Indeed, the informational benefits associated with the formation of a PTA are very much akin to those stemming from a fixed currency, which some studies (Chowdhury, 1993) suggest can be quite substantial.

${ }^{8}$ Of course, these results demonstrate that uncertainty negatively affects market participants on average. There may exist risk-loving market participants who benefit from an uncertain policy environment. For instance, certain firms may be better able to insure against policy risk - for instance, by virtue of credit constraints in accessing financial markets. For these firms, policy uncertainty acts as a barrier to entry, driving up their profits. All that is required for our results to hold is that the majority of market participants are risk-averse.

${ }^{9}$ Additional social costs may be incurred if PTAs generate trade diversion rather than trade creation - a particular threat for for 'spokes' in 'hub and spoke' trade areas (Wonnacott, 1996). However, the costs of trade diversion will be dominated by the benefits of uncertainty reduction and any additional welfare benefits stemming from trade creation in observed PTAs. Political leaders will be unwilling to enter into those agreements in which the distortions introduced by the agreement are such that their chances of survival in office are harmed.

${ }^{10}$ The concavity of the voters' loss function imposes risk-aversion by assumption. As noted above, a substantial literature in political economy finds that policy risk imposes costs on the average market participant. For instance, Feng (2001) finds that policy uncertainty depresses private sector investment - which suggests that the majority of investors are risk averse. Chowdhury (1993) finds that reductions in exchange rate volatility increase trade volumes - again indicating that the majority of traders are risk averse. In light of these empirical results, we are comfortable in making this assumption. Our results would continue to hold if a discrete number of voters varied in their degree of risk-aversion, so long as the median voter is risk-averse.

${ }^{11}$ We also assume that $\frac{1}{2} \alpha-\beta>0$ to ensure that the second-order condition on the executive's maximization problem is satisfied. This effectively puts an upper bound on the precision of the signal.

${ }^{12}$ We primarily focus on the role of tariff bindings in reducing the variance of the voters' signal. However, it may also be the case that the PTA makes trade policy formation more transparent - as other signatories or the PTA institution itself may report on policy changes. These effects are analytically identical in our model. All serve to reduce the variance of the publics' signal regarding the trade policy in force.

${ }^{13}$ Of course not all PTAs are identical in their effectiveness in reducing policy uncertainty. We do not treat them as such; we only make the assumption that more PTAs leads to more precise beliefs regarding policy. Moreover we are agnostic as to the marginal effect of additional PTAs on precision - the precision-enhancing effect of PTAs may be minimal after the 2nd, 3rd or 4th PTA. All we require is that the marginal effect is not negative.

${ }^{14}$ We do not distinguish between mechanisms through which PTAs might reduce policy uncertainty. While we stress the role of tariff bindings above, PTAs may also serve to make the policy formulation process more transparent. These two mechanisms are analytically identical in our model. And while it may be possible, in principal, to distinguish between these mechanisms, such a distinction is beyond the scope of the present work.

${ }^{15}$ Our data is such that we observe the precise data of leader entry and exit. All other observations are treated as 
ending on December 31st of a given year.

${ }^{16}$ Only periods under observation enter into the likelihood function. Thus, if a leader enters prior to 1995, she is only considered to be at risk from January 1, 1995 on.

${ }^{17}$ PTA formation has been argued to have been significantly affected by the international security concerns of the Cold War period. We eliminate any such concerns by confining our analysis to the post-Cold War period. Baccini and Dür rely largely on three databases for their data: the list of regional trade agreements notified to the WTO, the Tuck Trade Agreements Database and the McGill Faculty of Law Preferential Trade Agreements Database (at http://www.wto.org/english/tratop_e/region_e/ http://www.dartmouth.edu/ tradedb/; and http://ptas.mcgill.ca/). The EU is treated as a single entitity in the data, and countries that join the EU are coded as signing up for all trade agreements the EU is a member of at the time of accession.

${ }^{18}$ The functional form of the Cox proportional hazards specification - which is equivalent to that of a cloglog link function - will also induce diminishing marginal effects.

${ }^{19}$ In this analysis, we make use of the Polity IV dataset, given its widespread acceptance and use in this literature. We have replicated our analysis using the binary ACLP democracy measure as coded by Cheibub, Ghandi and Vreeland (2010), and results are substantively unchanged. These results are available from the authors on request.

${ }^{20}$ Note that the polity 2 variable name refers to the cumulative democracy score. Polity IV is the name of the index from which this variable is drawn.

${ }^{21}$ In the Table 6 in the appendix, we summarize the frequency with which PTAs are signed in periods surrounding an election in democracies (polity2 scores greater than or equal to 5). Somewhat surprisingly, democratic governments are less likely to sign a PTA in the year of or year prior to an election, despite the electoral advantages of PTAs. This relationship may arise because parties are elected following promises to enter into PTAs (and retained after their successful conclusion), because governments are pre-occupied with the election process, or because democratic opposition parties are less willing to agree to a PTA prior to an election. Data on election timing are drawn from Kelley and Kolev (2010). These data are pre-release, more information can be found at http://www.duke .edu/web/diem/data.html.

${ }^{22}$ Coefficients reported below reflect the values of $\gamma$; they have not been converted to hazard ratios.

${ }^{23}$ The Grambsch-Therneau and Harrell's rho tests rely respectively on the absolute cumulative sum of the Schoenfeld residuals and the correlations between covariate and residual values to test the hypothesis that the proportional hazards assumption doesn't hold against the null that it does.

${ }^{24}$ Results reported in the Appendix.

${ }^{25}$ It may be objected that a spurious correlation may exist between PTA signings and leadership survival. Leaders who survive longer in office may have greater opportunities to sign PTAs. Note, however, that this effect is at least partially controlled for by the Cox models, which adjusts for time dependency in the data. Moreover, if such a relationship exists, we would expect it to hold for both autocratic and democratic leaders. As the results below show, PTA signings improve the survival of democrats, but the effect on autocrats is quite weak.

${ }^{26}$ To control for potential selection on unobservables, it would be necessary to employ an instrumental variables based estimate of the probability that a given government enters into a PTA. We do not know of a term that adequately satisfies 
the exclusion restriction - i.e. a covariate that strongly affects the probability of entering into a PTA but that, conditional on the other regressors, does not effect regime survival. If the exclusion restriction is satisfied, IV estimates produce consistent estimates of the causal effect of PTA signings; though they do so at the cost of reduced efficiency. If the exclusion restriction is not satisfied, however, the IV estimates are both inconsistent and inefficient. Absent a plausible instrument, therefore, IV estimates should be avoided.

${ }^{27}$ The leftmost plot in Figure 2 - i.e., the plot depicting the hazard rate of autocrats - appears to show only a single curve. In reality, all three curves are plotted, but the difference in hazard rates between autocratic governments that sign no PTA, that sign one PTA, and that sign the maximal number of PTAs is so small that all three hazard curves are superimposed on one another. Thus, the signing of PTAs does not appear to affect autocratic survival in any meaningful way.

${ }^{28}$ Our approach also differs too in its empirical strategy. First, the regressor of interest in Mansfield and Milner (2009) is simply an indicator for PTA signings, while we consider the effect of the number of PTAs signed. Second, we directly test the conditional effect of PTA signings in democracies and non-democracies by including an interaction term in all our models. Mansfield and Milner restrict attention to democracies alone: they perform their estimates using country-years with polity scores (on a 0-20 scale) greater than 17 . Third, we address the problem of endogeneity, and particularly the possibility of endogenous selection into PTAs, and adopt measures to deal with this problem: we preprocess our data to generate a matched and balanced dataset, significantly reducing problems of covariate balance associated with selection on observables.

\section{References}

Abbott, Frederick M. 2000. "The NAFTA and the Legalization of World Politics." International Organization 54:519.

Ai, Chunrong and Edward C. Norton. 2003. "Interaction Terms in Logit and Probit Models." Economic Letters 80:123-129.

Aizenman, Joshua and Nancy P. Marion. 1993. "Policy Uncertainty, Persistence and Growth." Review of International Economics 1(2):145-163.

Baccini, Leonardo and Andreas Dur. 2009. "The New Regionalism and Policy Interdependence." International Studies Quarterly forthcoming.

Bagwell, Kyle and Robert W. Staiger. 1999. "An Economic Theory of the GATT." American Economic Review 89(1):215-248.

Baldwin, Richard E. 1994. Towards an Integrated Europe. Technical report Report to the Euorpean Commission.

Berry, William D., Jacqueline H.R. DeMeritt and Justin Esarey. 2010. "Testing for Interaction Effects in Binary Logit and Probit Models: Is an Interaction Term Necessary." The American Journal of Political Science 54(1):248-266.

Bhagwati, Jagdish N. 2008. Termites in the trading system: How Preferential Agreements Undermine Free Trade. New York: Oxford University Press. 
Box-Steffensmeier, Janet M. and Bradford S. Jones. 2004. Event History Modeling: A Guide for Social Scientists. Cambridge University Press.

Broz, J. Lawrence. 2002. "Political System Transparency and Monetary Commitment Regimes." International Organization 56(4):861-887.

Bueno de Mesquita, Bruce, Alastair Smith, Randolph M. Siverson and James D. Morrow. 2003. The Logic of Political Survival. Cambridge, MA: The MIT Press.

Cheibub, Jose Antonio, Jennifer Ghandi and James Raymond Vreeland. 2010. "Democracy and Dictatorship Revisited." Public Choice 143(1-2):67-101.

Chowdhury, Abdur R. 1993. "Does Exchange Rate Volatility Depress Trade Flows? Evidence from Error-Correction Models." Review of Economics and Statistics 75:700-706.

Dixit, Anivash. 1989. "Trade Insurance and Adverse Selection." Review of Economics and Statistics 56:235-247.

Dixit, Anivash and John Londregan. 1995. "Redistributive Politics and Economic Theory." The American Political Science Review 89(4):856-866.

Dixit, Avinash. 1996. The Making of Economic Policy: A Transactions-Cost Politics Perspective. Cambridge: MIT Press.

Downs, George W. and David M. Rocke. 1995. Optimal Imperfection? Princeton University Press.

Eaton, Jonathan and Gene M. Grossman. 1985. "Tariffs as Insurance: Optimal Commercial Policy When Domestic Markets Are Incomplete.” Canadian Journal of Economics 18:258-273.

Feng, Yi. 2001. "Political Freedom, Political Instability, and Policy Uncertainty: A Study of Political Institutions and Private Investment in Developing Countries." International Studies Quarterly 45:271-294.

Fernandez, Raquel and Jonathan Portes. 1998. "Returns to Regionalism: An Analysis of Nontraditional Gains from Regional Trade Agreements." The World Bank Economic Review 12(2):197-220. URL: http://wber.oxfordjournals.org/cgi/content/abstract/12/2/197

Francois, Joseph F. and Will Martin. 2004. "Commercial policy variability, bindings, and market access." European Economic Review 48:665-679.

Frieden, Jeffrey A. 2002. "Real Sources of European Currency Policy: Sectoral Interests and European Monetary Integration.” International Organization 56(4):831-60.

Fudenberg, Drew and Jean Tirole. 1991. Game Theory. The MIT Press.

Gelman, Andrew and Jennifer Hill. 2006. Data Analysis Using Regression and Multilevel/Hierarchical Models. Analytical Methods in Social Science Cambridge University Press.

Goemans, Hein. 2006. Archigos: A Database on Political Leaders. Paper Presented at the Annual Meeting of the American Political Science Association.

Gowa, Joanne and Edward D. Mansfield. 1993. "Power Politics and International Trade." American Political Science Review 87(2):Gowa, Joanne, and Edward D. Mansfield, "Power Politics and International Trade" in 408-420. 
Greene, William. 2010. "Testing Hypothesis About Interaction Terms in Nonlinear Models." Economic Letters 107:291-296.

Greene, William H. 2002. Econometric Analysis. 5th ed. Prentice-Hall, Inc.

Hafner-Burton, Emilie M. 2005. “Trading Human Rights: How Preferential Trade Agreements Influence Government Repression.” International Organization 59(3):593-629.

Heston, Alan, Robert Summers and Bettina Aten. 2006. "Penn World Table Version 6.2." Center for International Comparisons of Production, Income and Prices at the University of Pennsylvania.

Ho, Daniel E., Kosuke Imai, Gary King and Elizabeth A. Stuart. 2007. "Matching as Preprossesing for Reducing Model Dependence in Parametric Causal Inference." Political Analysis (forthcoming).

Ho, Daniel, Kosuke Imai, Gary King and Elizabeth Stuart. 2004. "MatchIt: Matching as Nonparametri Preprocessing for Parametric Causal Inference.". http://gking.harvard.edu/matchit/.

Jackson, John H. 2004. "International Law Status of WTO Dispute Settlement Reports: Obligation to Comply or Option to "Buy Out"?" American Journal of International Law 98:109-125.

Johnson, Harry G. 1953. “Optimum Tariffs and Retaliation.” Review of Economic Studies 21(2):142153.

Kelley, Judith G. and Kiril Kolev. 2010. "Election Quality and International Observation 1975-2004: Two New Datasets." http://ssrn. com/abstract=1694654.

Krugman, Paul R. 1993. Regionalism versus Multilateralism: Analytical Notes. In New Dimensions in Regional Integration, ed. J. de melo and A. Panagariya. New York: Cambridge University Press.

Leblang, David and Shanker Satyanath. 2006. "Institutions, Expectations, and Currency Crises." International Organization 60(Winter):245-262.

Maggi, Giovanni and Andres Rodriguez-Clare. 1998. "The Value of Trade Agreements in the Presence of Political Pressures." Journal of Political Economy 106(3):574-601.

Mansfield, Edward D. and Eric Reinhardt. 2008. "International Institutions and the Volatility of International Trade." International Organization 62:621-652.

Mansfield, Edward D. and Helen V. Milner. 2009. "The Politics of International Cooperation: Trade, Democracy and Veto Players.".

Mansfield, Edward D., Helen V. Milner and B. Peter Rosendorff. 2000. "Free to Trade: Democracies, Autocracies and International Trade." American Political Science Review 94(2):305-322.

Mansfield, Edward D., Helen V. Milner and B. Peter Rosendorff. 2002. "Why Democracies Cooperate More: Electoral Control and International Trade Agreements." International Organization 56(3):477-514.

Mansfield, Edward D., Helen V. Milner and Jon C. Pevehouse. 2007. "Vetoing Co-operation: The Impact of Veto Players on Preferential Trading Arrangements." British Journal of Political Science 37(3):403-32.

Marshall, Monty G. and Keith Jaggers. 2000. "Polity IV Project: Political Regime Characteristics and Transitions, 1800-1999." www.bsos.umd.edu/cidcm/inscr/polity December. 
MERCOSUR: Objectives and Achievements. 1997. World Trade Organization Staff Working Paper TPRD9702.WPF.

Milner, Helen. V. and B. Peter Rosendorff. 1997. "Trade Negotiations, Information and Domestic Politics." Economics and Politics .

Milward, Alan S. 1992. The European Rescue of the Nation-State. 2nd. ed. Routledge.

Morgan, Stephen L. and Christopher Winship. 2007. Counterfactuals and Causal Inference. Cambridge University Press.

Nagler, Jonathan. 1991. "The Effect of Registration Laws and Education on U.S. Voter Turnout." The American Political Science Review 85:1393-1405.

Nielsen, Richard and Beth A. Simmons. 2009. "Rewards for Rights Ratification? Testing for Tangible and Intangible Benefits of Human Rights Treaty Ratification.".

Pahre, Robert. 2008. Politics and Trade Cooperation in the Nineteenth Century: the "Agreeable Customs. New York: Cambridge University Press.

Pevehouse, Jon C., Emilie Hafner-Burton and Matthew Zierler. 2002. "Regional Trade and Institutional Design: Long After Hegemony?" Unpublished, University of Wisconsin. Presented at the 2002 MPSA Meetings.

Rodrik, Dani. 1991. "Policy Uncertainty and Private Investment in Developing Countries." Journal of Development Economics 36:229-2442.

Rosendorff, B. Peter. 2005. "Stability and Rigidity: Politics and the Design of the WTO's Dispute Resolution Procedure." The American Political Science Review 99(3):389-400.

Simmons, Beth A. and Daniel J. Hopkins. 2005. "The Constraining Power of International Treaties: Theory and Methods." The American Political Science Review 99(4):623-631.

Tobin, Jennifer L. and Marc L. Busch. 2010. "A BIT is Better than a Lot: Bilateral Investment Treaties and Preferential Trade Agreements." World Politics 62:1-42.

van Wijnbergen, Sweder. 1992. "Trade Reform, Policy Uncertainty, and the Current Account: A Non-Expected Utility Approach.” American Economic Review 82(3):626-633.

von Stein, Jana. 2005. "Do Treaties Constrain or Screen? Selection Bias and Treaty Compliance." The American Political Science Review 99(4):611-622.

Wonnacott, Ronald J. 1996. "Free Trade Agreements: For Better or Worse." American Economic Review 86(2):62-66. 


\section{Appendix: Proofs}

\section{Proposition 1}

Proof.

$$
\begin{aligned}
E(G(a, t, \alpha) \mid t) & =\Delta R \int\left(1-e^{-\beta C} e^{\beta \eta^{2}}\right) \frac{\sqrt{\alpha}}{\sqrt{2 \pi}} e^{-\frac{1}{2} \alpha \eta^{2}} d \eta+(1-\Delta) R-\frac{1}{2} \alpha^{2} \\
& =\Delta R\left[1-e^{-\beta C}\left(\frac{\frac{1}{2} \alpha}{\frac{1}{2} \alpha-\beta}\right)^{\frac{1}{2}}\right]+(1-\Delta) R-\frac{1}{2} \alpha^{2}
\end{aligned}
$$

since $\int_{-\infty}^{\infty} e^{-k x^{2}} d x=\frac{\sqrt{\pi}}{\sqrt{k}}$.

Maximizing over $\alpha, \frac{d}{d \alpha} E G(a, t, \alpha)=\Delta R \beta e^{-\beta C} \frac{1}{4}\left(\frac{1}{2} \alpha\right)^{-\frac{1}{2}}\left(\frac{1}{2} \alpha-\beta\right)^{-\frac{3}{2}}-\alpha=0$. Solving, this yields two solutions $\alpha=\beta \pm \sqrt{\beta^{2}+\left(\Delta \frac{R \beta}{e^{C \beta}}\right)^{\frac{2}{3}}}$. Checking the second order condition, $\frac{d^{2}}{d \alpha^{2}} E G(a, t, \alpha)=$ $2 \Delta R \beta e^{-\beta C}(\alpha)^{-\frac{3}{2}}(\alpha-2 \beta)^{-\frac{5}{2}}(\beta-2 \alpha)-1$. Now $\frac{1}{2} \alpha-\beta>0$ by assumption. Therefore $\frac{d^{2}}{d \alpha^{2}} E G(a, t, \alpha)<$ 0 implies $\alpha=\beta+\sqrt{\beta^{2}+\left(R \Delta \beta e^{-C \beta}\right)^{\frac{2}{3}}}$. Recall that $\alpha(n)$ is strictly monotonic and continuous and hence invertible. Then $\beta+\sqrt{\beta^{2}+\left(R \Delta \beta e^{-C \beta}\right)^{\frac{2}{3}}}=\alpha(n)$ and $n=\alpha^{-1}\left[\beta+\sqrt{\beta^{2}+\left(R \Delta \beta e^{-C \beta}\right)^{\frac{2}{3}}}\right]$.

\section{Proposition 2}

Proof. Totally differentiating the first order condition, we have $\frac{d}{d \alpha} E G(a, t, \alpha)=0$, we have $\frac{d}{d \alpha} \frac{d}{d \alpha} E G(a, t, \alpha) d \alpha+$ $\frac{d}{d \Delta} \frac{d}{d \alpha} E G(a, t, \alpha) d \Delta=0$. Then $\frac{d \alpha}{d \Delta}=-\frac{\frac{d}{d \Delta} \frac{d}{d \alpha} E G(a, t, \alpha)}{\frac{d^{2}}{d \alpha^{2}} E G(a, t, \alpha)}=-\frac{R \beta e^{-\beta C} \frac{1}{4}\left(\frac{1}{2} \alpha\right)^{-\frac{1}{2}}\left(\frac{1}{2} \alpha-\beta\right)^{-\frac{3}{2}}}{\frac{d^{2}}{d \alpha^{2}} E G(a, t, \alpha)}>0$ since $\alpha-2 \beta>0$ and $\frac{d^{2}}{d \alpha^{2}} E G(a, t, \alpha)<0$ by the second order condition. Recall that $\alpha(n)$ is strictly increasing and continuous, hence invertible, which means $\frac{d n}{d \alpha}>0$. Then $\frac{d n}{d \Delta}=\frac{d n}{d \alpha} \frac{d \alpha}{d \Delta}>0$.

\section{Proposition 3}

Proof. $\quad \frac{d \alpha}{d R}=-\frac{\frac{d}{d R} \frac{d}{d \alpha} E G(a, t, \alpha)}{\frac{d^{2}}{d \alpha^{2}} E G(a, t, \alpha)}$. From the first order condition, $\frac{d}{d \alpha} E G(a, t, \alpha)=\Delta R e^{-\beta C} \frac{1}{4}\left(\frac{\frac{1}{2} \alpha}{\frac{1}{2} \alpha-\beta}\right)^{-\frac{1}{2}} \frac{\beta}{\left(\frac{1}{2} \alpha-\beta\right)^{2}}-\alpha$.

$\frac{d \alpha}{d R}=-\frac{\frac{d}{d R} \frac{d}{d \alpha} E G(a, t, \alpha)}{\frac{d^{2}}{d \alpha^{2}} E G(a, t, \alpha)}=-\frac{\Delta e^{-\beta C} \frac{1}{4}\left(\frac{\frac{1}{2} \alpha}{\frac{1}{2} \alpha-\beta}\right)^{-\frac{1}{2}} \frac{\beta}{\left(\frac{1}{2} \alpha-\beta\right)^{2}}}{\frac{d^{2}}{d \alpha^{2}} E G(a, t, \alpha)}>0$ since $\frac{1}{2} \alpha-\beta>0$ and $\frac{d^{2}}{d \alpha^{2}} E G(a, t, \alpha)<0$. As before, $\frac{d n}{d R}=\frac{d n}{d \alpha} \frac{d \alpha}{d R}>0$.

\section{Lemma 1}


Proof. Follows from proof of proposition 1.

\section{Proposition 4}

Proof. The expected prob of survival $E[\operatorname{Pr}\{$ survival $\}]=\Delta E P(W(a, t))+(1-\Delta)=\Delta\left[1-e^{-\beta C}\left(\frac{\frac{1}{2} \alpha}{\frac{1}{2} \alpha-\beta}\right)^{\frac{1}{2}}\right]+$ $(1-\Delta)=1-\Delta e^{-\beta C}\left(\frac{\frac{1}{2} \alpha}{\frac{1}{2} \alpha-\beta}\right)^{\frac{1}{2}}$. By definition, $\alpha=\alpha(n)$.

Proof of a:

$\frac{\partial}{\partial n} E[\operatorname{Pr}\{$ survival $\}]=-\Delta e^{-\beta C} \frac{\partial}{\partial \alpha}\left(\frac{\frac{1}{2} \alpha}{\frac{1}{2} \alpha-\beta}\right)^{\frac{1}{2}} \frac{\partial \alpha}{\partial n}=-\Delta e^{-\beta C} \frac{1}{2}\left(\frac{\frac{1}{2} \alpha}{\frac{1}{2} \alpha-\beta}\right)^{-\frac{1}{2}} \frac{-\beta}{\left(\frac{1}{2} \alpha-\beta\right)^{2}} \frac{\partial \alpha}{\partial n}$

$=\Delta e^{-\beta C} \frac{1}{2}\left(\frac{\frac{1}{2} \alpha}{\frac{1}{2} \alpha-\beta}\right)^{-\frac{1}{2}} \frac{\beta}{\left(\frac{1}{2} \alpha-\beta\right)^{2}} \frac{\partial \alpha}{\partial n}>0$ since $\frac{1}{2} \alpha-\beta>0$ and $\frac{\partial \alpha}{\partial n}>0$.

Proof of $b$.

$\frac{\partial}{\partial \Delta} E[\operatorname{Pr}\{$ survival $\}]=-e^{-\beta C}\left(\frac{\frac{1}{2} \alpha}{\frac{1}{2} \alpha-\beta}\right)^{\frac{1}{2}}<0$.

\section{Appendix: List of Countries in the Analysis}

Albania,Argentina, Armenia, Australia, Austria, Bahrain, Bangladesh, Belgium, Benin, Bolivia, Botswana, Brazil, Bulgaria, Burkina Faso, Burundi, Cambodia, Cameroon, Canada, CAF, Chile, China (PRC), Colombia, Costa Rica, Côte D’Ivoire, Croatia, Cuba, Czech Republic, Denmark, Djibouti, Dominican Republic, Ecuador, Egypt, El Salvador, Fiji, France, Gabon, The Gambia, Georgia, Germany, Ghana, Greece, Guatemala, Guinea, Guyana, Honduras, Hungary, India, Indonesia, Ireland, Israel, Italy, Jamaica, Japan, Jordan, Kenya, Korea, Republic of, Kyrgyzstan, Lithuania, Macedonia, Madagascar, Malawi, Malaysia, Mali, Mauritania, Mauritius, Mexico, Moldova, Mongolia, Morocco, Mozambique, Namibia, Nepal, Netherlands, New Zealand, Nicaragua, Niger, Nigeria, Norway, Oman, Pakistan, Panama, Papua New Guinea, Paraguay, Peru, Philippines, Portugal, Qatar, Romania, Rwanda, Saudi Arabia, Senegal, Singapore, Slovenia, South Africa, Spain, Sri Lanka, Swaziland, Sweden, Switzerland, Taiwan, Tanzania, Thailand, Togo, Trinidad and Tobago, Tunisia, Turkey, Uganda, UAE, United Kingdom, United States, Uruguay, Venezuela, Zambia, Zimbabwe 
Table 6: PTAs and Election Timing

\begin{tabular}{lcc}
\hline \hline & Frequency of PTA Formation & Standard Error \\
\hline Non-election period & 0.385 & 0.028 \\
Election Period & 0.310 & 0.024 \\
\hline Difference & 0.075 & 0.037 \\
\hline \hline
\end{tabular}

The fraction of election periods and non-election periods in which at least one PTA is signed. A year is defined as belonging to an election period if an election if either an executive or legislative election is held in that year or in the following year. Data on the timing of elections are drawn from Kelley and Kolev (2010). To construct our measure, we collapse that dataset such that the observation in the country year. We then code a dummy variable equal to 1 if there is either an executive election or legislative election in year $t$ or year $t+1$.

\section{Appendix: The Timing of Elections and PTA Formation}

\section{Appendix: Matching}

Table 7: Matching Estimates

\begin{tabular}{l|c}
\hline \hline \multirow{2}{*}{ Polity2 } & Matching Model \\
& $-.047^{*}$ \\
GDP per capita & $.026)$ \\
& $(.00002$ \\
Openness & .004 \\
Growth & $(.003)$ \\
& -.015 \\
Constant & $(.029)$ \\
& $-.837^{* * *}$ \\
& $(.307)$ \\
\hline $\mathrm{N}$ & 308 \\
\hline \hline
\end{tabular}

Results from a logit regression of PTA signing on Polity scores, and controls drawn from the Penn World Tables 6.2. Standard errors are reported in parentheses. ${ }^{* * *}$ implies significance at the 99 percent level, ${ }^{* *}$ implies significance at the 95 percent level, and * implies significance at the 90 percent level. 
Figure 3: Propensity Score Distributions: Pre- and Post-Matching

\section{Distribution of Propensity Scores}

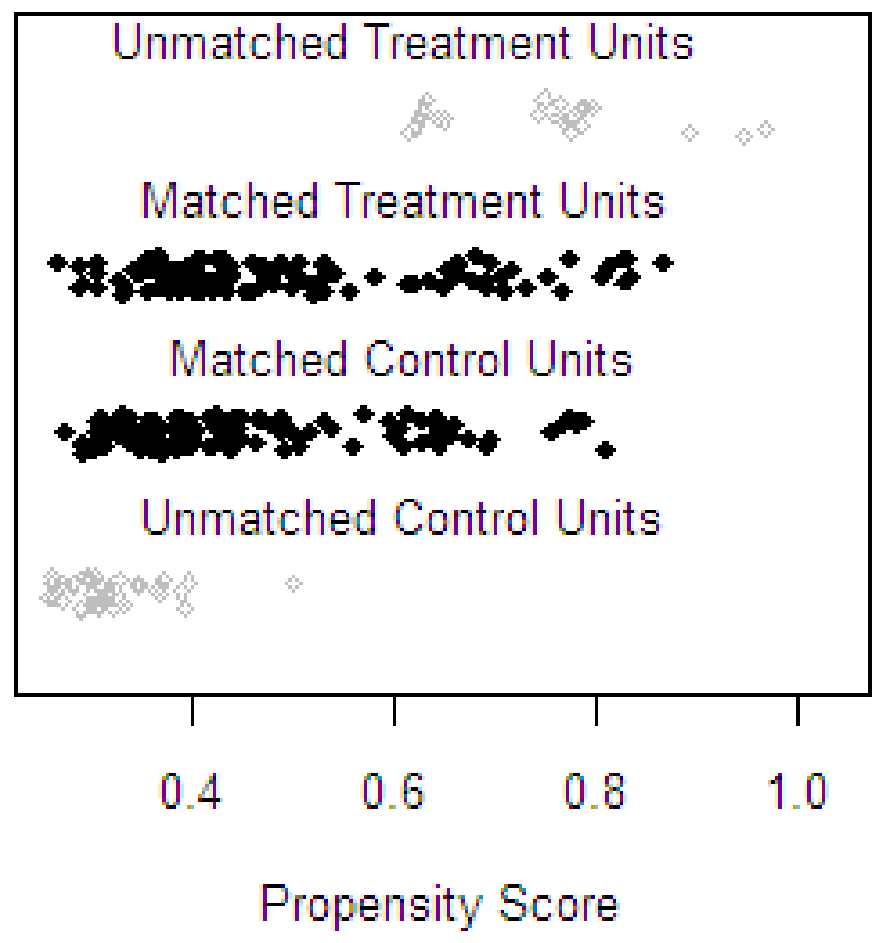



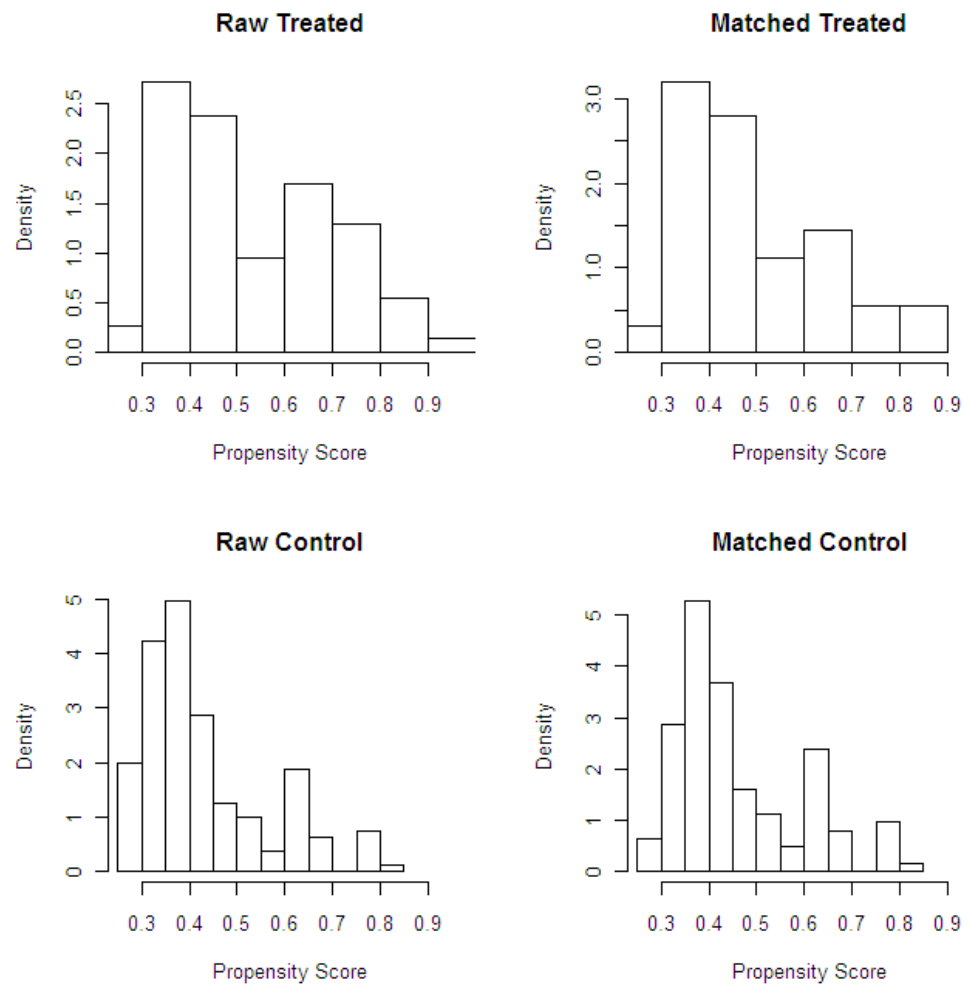

Plots of the distribution of propensity scores amongst leaders that signed ('Treated Units') and did not sign ('Control Units') PTAs. The more similar the distribution of propensity scores after matching, the more successful the matching procedure. The greater the initial divergence, the greater the dangers posed by selection on observables. 
Figure 4: Quantile-Quantile Plots

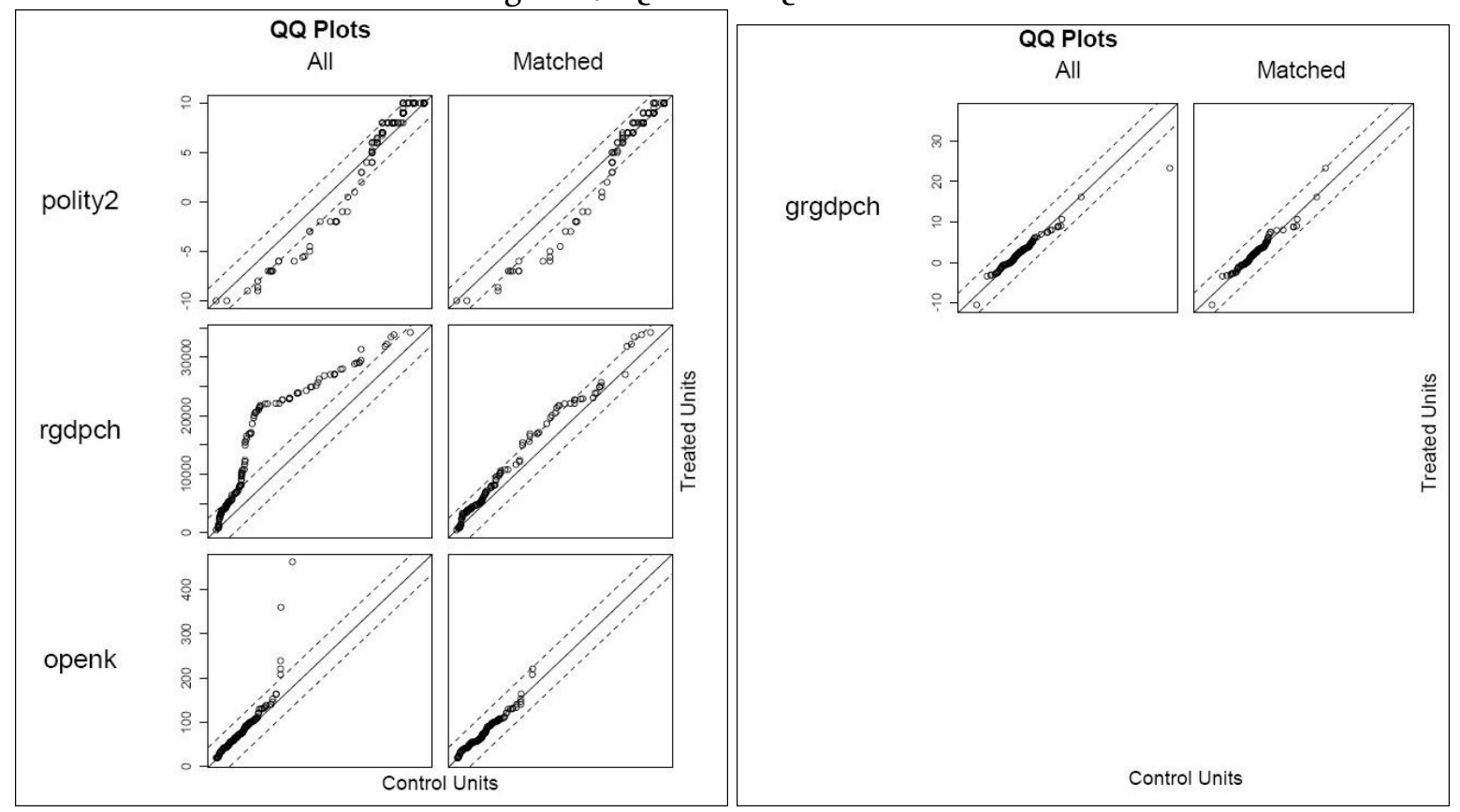

Quantile-Quantile (QQ) plots of the distribution of the regressors amongst leaders that signed ('Treated Units') and did not sign ('Control' Units) PTAs. Each treated observation is paired with a control observation taken from the same quantile in each distribution. The value the treated observation takes on is plotted on the y-axis; while that the control observation takes on is plotted on the x-axis. The closer the resultant plot lies to the 45 degree line, the greater on confidence that both samples are drawn from the same distribution and the less one need be concerned with problems of covariate balance. The polity2 variable is the Polity (-10 to 10) score drawn from the Polity IV dataset. The rgdpch variable is GDP per capita in PPP terms drawn from the Penn World Tables. openk denotes $\frac{\text { Exports Imports }}{G D P}$, also from the Penn World Tables. And grgdpch is the percentage growth rate in GDP, in constant chain-series dollars, from the Penn World Tables. 


\section{Appendix: Tests of the Proportional Hazards Assumption}

Table 8: Proportional Hazards Test: Pre-Matching

\begin{tabular}{l|cccc}
\hline \hline Variable & $\rho$ & $\chi^{2}$ & df & p-value \\
\hline Harrell's rho & & & & \\
Log(PTAnumber) & 0.14687 & 3.98 & 1 & 0.0460 \\
Polity2 & 0.15153 & 8.53 & 1 & 0.0035 \\
Log(PTAnumber)*Polity2 & -0.11206 & 2.55 & 1 & 0.1104 \\
GDP per capita & -0.01598 & 0.10 & 1 & 0.7536 \\
Openness & 0.10271 & 4.29 & 1 & 0.0382 \\
Growth & -0.02661 & 0.19 & 1 & 0.6628 \\
\hline Grambsch-Therneau & & & & \\
global test & & 16.73 & 6 & 0.0103 \\
\hline \hline
\end{tabular}

Table 9: Proportional Hazards Test: Post-Matching

\begin{tabular}{l|cccc}
\hline \hline Variable & $\rho$ & $\chi^{2}$ & df & p-value \\
\hline Harrell's rho & & & & \\
Log(PTAnumber) & 0.17894 & 4.75 & 1 & 0.0292 \\
Polity2 & 0.15116 & 6.18 & 1 & 0.0129 \\
Log(PTAnumber)*Polity2 & -0.10609 & 1.76 & 1 & 0.1846 \\
GDP per capita & -0.02728 & 0.18 & 1 & 0.6707 \\
Openness & 0.06861 & 1.02 & 1 & 0.3126 \\
Growth & -0.14361 & 4.68 & 1 & 0.0306 \\
\hline Grambsch-Therneau & & 15.99 & 6 & 0.0138 \\
global test & & & \\
\hline \hline
\end{tabular}

